\title{
New Physiologically Active Kaempferol Glucoside from Abutilon pannosum.
}

\author{
Abdullah I. Kamel \\ Chemistry Department \\ Faculty of Science \\ Mansoura University \\ Mansoura, Egypt
}

\author{
Manal G. Elfedawy \\ Chemistry Department \\ Faculty of Science \\ Mansoura University \\ Mansoura, Egypt
Mamdouh Abdel-Mogib Mansoura University
Mansoura, Egypt \\ Chem. Dept., Fac. of Sci.,
}

\author{
Maha M.ElShamy \\ Botany Department \\ Faculty of Science \\ Mansoura University \\ Mansoura, Egypt |
}

\begin{abstract}
:
The phytochemical investigation of Abutilon pannosum (Malvaceae) collected from arable land of Tennidah village, Dakhla Oasis, Western Desert, Egypt, resulted in the separation and identification of a new flavonoid, kaempferol 4'-O-(6"-O-E- $p$-coumaroyl)- $\beta$-Dglucopyranoside 1 from butanol fraction, in addition to the identification of the volatile constituents of petroleum ether and methylene chloride by GC/MS analysis. Structure of the separated compound was elucidated by spectral analysis. Additionally, the antimicrobial, antioxidant activities and cytotoxicity of different fractions of Abutilon pannosum and compound $\mathbf{1}$ were evaluated. The antimicrobial activity indexes of methanol extract (Ap C), compound 1, methylene chloride extract (Ap B) and petroleum ether extract (Ap A) against Escherichia coli were found to be $66.7 \%, 50.0 \%, 33.3 \%$, and $0.0 \%$, respectively. While the activity indexes of compound 1, (Ap B), (Ap C), (Ap A) against staphylococcus aureus were $68.2 \%, 63.6 \%, 59.1 \%$ and $9.1 \%$, respectively, and against Candida albicans, their activity indexes were $38.8 \%, 38.5 \%, 34.6 \%$, and $11.5 \%$, respectively. The radical scavenging activity of the extracts and standard were found to be in the following order: ascorbic acid $(88.6 \%)>(\mathrm{Ap} \mathrm{C})(84.4 \%)>$ compound $\mathbf{1}(76.8 \%)>(\mathrm{Ap} \mathrm{B})(59.2 \%)>(\mathrm{Ap} \mathrm{A})(6.3 \%)$. The IC50 values against HePG2 indicated that the cytotoxicity of extracts decreased in the order: compound 1 was "very strong", (Ap C) was "strong", (Ap B) was "moderate", and (Ap A) was "weak", while against PC3 of compound 1 was "strong", (Ap B and Ap C) were "moderate", and (Ap A) was weak, and against MCF-7 compound 1 and (Ap C) were "strong", (Ap B) was "moderate", and (Ap A) was "non-cytotoxic.
\end{abstract}

Keywords: Malvaceae, Abutilon pannosum, flavonoid, kaempferol 4'-O-(6"-O-E-p-coumaroyl)- $\beta$-D-glucopyranoside, antimicrobial activity, radical scavenging activity, cytotoxicity.

\subsection{INTRODUCTION}

The Malvaceae, or the mallows, are a family of flowering plants estimated to contain 243 genera with $4225+$ species [1]. Well-known members of this family include okra, cotton, and cacao. The genus Abutilon is one of the larger genera of the family Malvaceae [2]. Many authors recorded A. pannosum in Eastern Desert of Egypt [3, 4]. A. pannosum (G.Forst.) Schltdl. was recorded at edges of cultivation and arable lands in some oasis of Southern part of Western Desert [5]. On March 2014, it was collected from, Esbet-Qattara at El-Monira village nearby Pharous Temple, Kharga Oasis (N 2538'38.64" -E 30 38'38.88") and at Tennidah village (N 2530'31.08"- E $29^{\circ} 19^{\prime} 57.84$ ") in Dakhla Oasis as a part of Nubian Sothern part of Western Desert, Egypt, along road sides and arable lands. Plantations and other cultivated areas are the preferred habitats of A. pannosum [5]. A. pannosum is a Chaemophyte, Perennial shrubby herb, $1-3 \mathrm{~m}$, with erect or spreading stems branch out from the base. The stems are covered with yellow hairs. The heart-shaped leaves are velvety on both surfaces and have irregularly toothed edges. The flowers are located on the ends of long stalks, and are either solitary or found in clusters. Each flower has five petals which are approximately two centimeters long, and are either yellow or orange with a dark red to purple base. It produces small, rounded fruits which have obvious ridges and furrows. Each fruit is densely packed with flat mericarps. The brown, hairy seeds are usually kidney-shaped. The flowering period is between January and June [6]. A. pannosum is found in tropical Africa, including Djibouti, Eritrea, northern Ethiopia, Egypt and Sudan, and across to West Africa and the Cape Verde Islands. This species also occurs in Asia, where it is found in Saudia Arabia, the United Arab Emirates, Pakistan and India. In Pakistan, it is restricted to Sindh [7].

Preliminary phytochemical screening of A. pannosum showed the presence of Alkaloids, cardiac glycosides and steroids [8], 
seven known compounds namely, lupeol, beta-sitosterol, stigmasterol, methyl-4-hydroxybenzoate, taraxacin, ursolic acid, and beta-sitosterol-3-O-beta-D-glucopyranoside, have been isolated from the EtOAc soluble fraction of A. pannosum [9].

In this article, we present the results of the phytochemical reinvestigation, as well as the antimicrobial, antioxidant and antitumor activities of Abutilon pannosum.

\section{RESULTS AND DISCUSSION}

\subsection{Phytochemical evaluation}

Separation of butanol extract (Ap D) of Abutilon pannosum afforded a new natural product, kaempferol 4'-O-(6"-O-E- $p$ coumaroyl)- $\beta$-D-glucopyranoside 1. Additionally, the petroleum ether (Ap A) and methylene chloride (Ap B) fractions were analyzed by GC/MS. A sample from (Ap A) extract afforded 31 compound, with n-nonadecane (8.28\%), neicosane $(7.63 \%)$, n-octadecane $(7.31 \%)$, n-heptadecane (7.29\%), and n-hexadecane $(6.54 \%)$ being the major components. A sample from (Ap B) extract afforded 29 compound, with phytol (31.69\%), squalene (15.76\%), neophytadiene $(5.58 \%)$, and n-hexadecanoic acid (4.97\%) being the major components. NMR guided chromatographic separation led to two promising sub-fractions that were analyzed by GC/MS. A petroleum ether sub-fraction (Ap a) afforded 15 compound, with methyl palmitate $(38.98 \%)$ as a major component, and a methylene chloride sub-fraction (Ap b) afforded 9 compounds with squalene $(61.71 \%$ ) as a major component. Compound 1 was identified by spectral analysis. The ${ }^{1} \mathrm{H}$ NMR spectrum (Table 1) showed a signal pattern of a kaempferol derivative with $\mathrm{H}-6, \mathrm{H}-8$ signals of ring $\mathrm{A}$ at $\delta 6.21$, 6.39, in agreement with 5,7-dihydroxy $[\mathbf{1 0}, \mathbf{1 1}]$, and AA'BB' spin system of ring B with coupling of $8.4 \mathrm{~Hz}$ at $\delta 7.97$ and 6.79 , indicating the probable 4 '-substitution.The spectrum showed also signals of a glucose unit, with the anomeric proton signal at $\delta 5.46$ as a doublet with $\mathrm{J}$ of $7.2 \mathrm{~Hz}$, indicating a $\beta$-Dglucopyranoside. The signals of $\mathrm{H}-6$ protons shifted downfield at $\delta 4.05,4.28$ indicating the probable esterification to $p$ coumaroyl that gave AA'BB' spin system at $\delta 6.86,7.38$ and the ethylenic $\mathrm{H}-7, \mathrm{H}-8$ at $\delta 6.12,7.35$ as a pair of doublets with trans coupling of $16 \mathrm{~Hz}$. The probable glycosidation at C-3-OH was excluded on the bases of notable shifts of ring $\mathrm{B}$ signals $[10,11]$. Thus, 1 was identified as kaempferol 4'-O-(6"-O-E-pcoumaroyl)- $\beta$-D-glucopyranoside, rather than its isomer cephacoside, isolated previously from the same species [9].The proposed structure for $\mathbf{1}$ was confirmed by 1 - and 2-D NMR analysis

(DEPT,

HSQC,HMBC)

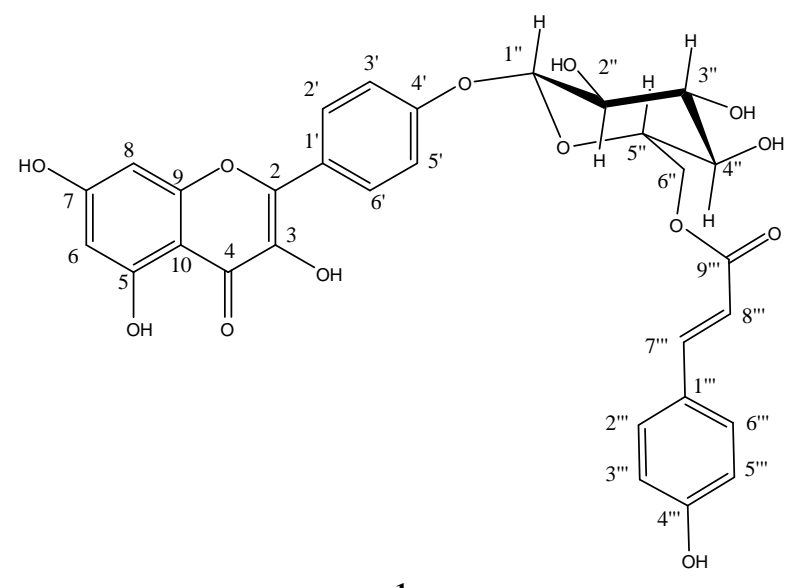

\subsection{Biological applications}

\subsubsection{Antimicrobial activity assessment}

The antimicrobial activity indexes of methanol extract (Ap C), compound 1, methylene chloride extract (Ap B) and petroleum ether extract (Ap A) were presented in Table 2 against Escherichia coli were found to be $66.7 \%$, 50\%, 33.3\%, and $0.0 \%$, respectively. While the activity indexes of compound 1, (Ap B), (Ap C), and (Ap A) against staphylococcus aureus were $68.2 \%, 63.6 \%, 59.1 \%$ and $9.1 \%$, respectively, and against Candida albicans, their activity indexes were $38.8 \%, 38.5 \%, 34.6 \%$, and $11.5 \%$, respectively (table 2).

\subsubsection{Free radical scavenging activity assessment}

The anti-oxidant activities of the extracts of A. pannosum were presented in Table 3 by (ABTS) method $[12,13,14]$. Methanol extract (Ap C) had the highest scavenging activity. The radical scavenging activity of the extracts and standard decreased in the following order: ascorbic acid, methanol (Ap C), compound 1, methylene chloride (Ap B) and petroleum ether (Ap A) (table 3), respectively. 
Table3: ${ }^{1} \mathrm{H},{ }^{13} \mathrm{C}$ NMR and $\mathrm{HMBC}$ data of compound $\mathbf{1}$

\begin{tabular}{|c|c|c|c|c|}
\hline Position & ${ }^{1} \mathrm{H}$ (multiplicity, J) & ${ }^{13} \mathrm{C}$ & DEPT & Long range coupled protons, from HMBC \\
\hline 2 & --------------------------- & 160.44 & $\mathrm{C}$ & H-2',H-6' \\
\hline 3 & ---------------------------- & 133.49 & $\mathrm{C}$ & 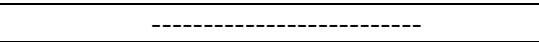 \\
\hline 4 & ----------------------------- & 177.85 & $\mathrm{C}$ & --------------------------- \\
\hline 5 & ------------------------------- & 156.81 & $\mathrm{C}$ & \\
\hline 6 & $6.21, \quad(\mathrm{IH}, \mathrm{br} . \mathrm{s})$ & 99.23 & $\mathrm{CH}$ & 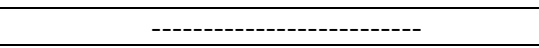 \\
\hline 7 & - & 164.64 & $\mathrm{C}$ & --------------------------- \\
\hline 8 & $6.39, \quad(\mathrm{IH}$, br.s $)$ & 94.13 & $\mathrm{CH}$ & 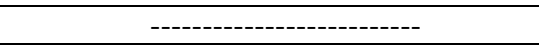 \\
\hline 9 & -------------------------- & 156.90 & $\mathrm{C}$ & $\mathrm{H}-8$ \\
\hline 10 & 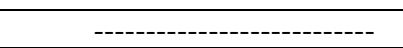 & 104.31 & $\mathrm{C}$ & H-6 \\
\hline $1^{\prime}$ & ------------------------------ & 125.36 & $\mathrm{C}$ & H-3',H-5' \\
\hline $2^{\prime} \& 6^{\prime}$ & $7.97, \quad(2 \mathrm{H}, \mathrm{d}, \mathrm{J}=8.4 \mathrm{HZ})$ & 131.28 & $\mathrm{CH}$ & --------------------------- \\
\hline $3^{\prime} \& 5^{\prime}$ & $6.79, \quad(2 \mathrm{H}, \mathrm{d}, \mathrm{J}=8.4 \mathrm{HZ})$ & 116.21 & $\mathrm{CH}$ & -------------------------- \\
\hline $4^{\prime}$ & ------------------------------ & 160.24 & $\mathrm{C}$ & H-2',H-6', H-3', H-5' \\
\hline $1 "$ & $5.46, \quad(1 \mathrm{H}, \mathrm{d}, \mathrm{J}=7.2 \mathrm{HZ})$ & 101.39 & $\mathrm{CH}$ & - ------------------------ \\
\hline $2 "$ & $3.37, \quad(\mathrm{IH}, \mathrm{m})$ & 74.67 & $\mathrm{CH}$ & ------------------------- \\
\hline $3 "$ & $3.28, \quad(\mathrm{IH}, \mathrm{m})$ & 76.65 & $\mathrm{CH}$ & ---------------------------- \\
\hline $4 "$ & $3.24, \quad(\mathrm{IH}, \mathrm{m})$ & 70.41 & $\mathrm{CH}$ & 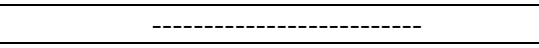 \\
\hline $5 "$ & $3.21, \quad(\mathrm{IH}, \mathrm{m})$ & 74.57 & $\mathrm{CH}$ & 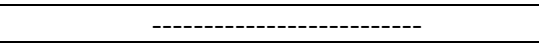 \\
\hline $6 " \mathrm{a}$ & $4.28,(1 \mathrm{H}$, br.d, $\mathrm{J}=12 \mathrm{HZ})$ & 63.40 & $\mathrm{CH}_{2}$ & 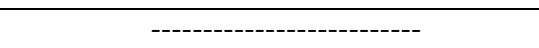 \\
\hline $6 " \mathrm{~b}$ & $4.05,(1 \mathrm{H}, \mathrm{dd}, \mathrm{J}=12,5.2 \mathrm{HZ})$ & & & \\
\hline $1 " '$ & --------------------- & 121.21 & $\mathrm{C}$ & H-2"',H-6"' \\
\hline 3 "' \& 5"' & $6.86, \quad(2 \mathrm{H}, \mathrm{d}, \mathrm{J}=8.4 \mathrm{HZ})$ & 115.54 & $\mathrm{CH}$ & H-3"',H-5'"' \\
\hline 2 "' \& 6"' & $7.38, \quad(2 \mathrm{H}, \mathrm{d}, \mathrm{J}=8.4 \mathrm{HZ})$ & 130.61 & $\mathrm{CH}$ & H-3"',H-5"', H-7"' \\
\hline $4 " '$ & ------------------------------ & 161.59 & $\mathrm{C}$ & H-2"',H-6"',H-3"',H-5"' \\
\hline $7^{\prime \prime \prime}$ & $7.35,(1 \mathrm{H}, \mathrm{d}, \mathrm{J}=16 \mathrm{HZ})$ & 145.06 & $\mathrm{CH}$ & H-3"',H-5"' \\
\hline $8 " 1$ & $6.12,(1 \mathrm{H}, \mathrm{d}, \mathrm{J}=16 \mathrm{HZ})$ & 114.07 & $\mathrm{CH}$ & \\
\hline 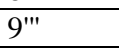 & ------------------------- & 166.63 & $\mathrm{C}$ & H-7"',H-8'" \\
\hline
\end{tabular}

Table 2: The inhibition zone in mm of the extracts of Abutilon pannosum and compound $\mathbf{1}$ compared to standard antibiotics [15]

\begin{tabular}{|l|c|c|c|c|c|c|}
\hline \multirow{2}{*}{$\begin{array}{l}\text { Compound / } \\
\text { Fraction }\end{array}$} & \multicolumn{2}{|c|}{ E. coli $(\mathrm{mg} / \mathrm{ml})$} & \multicolumn{2}{c|}{ S. aureus $(\mathrm{mg} / \mathrm{ml})$} & \multicolumn{2}{c|}{ C. Albicans (mg/ml) } \\
\cline { 2 - 7 } & $\begin{array}{l}\text { Diameter of } \\
\text { inhibition } \\
\text { zone (in mm) }\end{array}$ & $\begin{array}{l}\text { \% Activity } \\
\text { index }\end{array}$ & $\begin{array}{l}\text { Diameter of } \\
\text { inhibition zone } \\
\text { (in mm) }\end{array}$ & $\begin{array}{l}\text { \% Activity } \\
\text { index }\end{array}$ & $\begin{array}{l}\text { Diameter of } \\
\text { inhibition zone } \\
\text { (in mm) }\end{array}$ & $\begin{array}{l}\text { \% Activity } \\
\text { index }\end{array}$ \\
\hline $\mathbf{1}$ & 12 & 50 & 15 & 68.2 & 10 & 38.8 \\
\hline Ap B & 8 & 33.3 & 14 & 63.6 & 10 & 38.5 \\
\hline Ap C & 16 & 66.7 & 13 & 59.1 & 9 & 34.6 \\
\hline Ap A & NA & ---- & 2 & 9.1 & 3 & 11.5 \\
\hline Ampicillin & 24 & 100 & 22 & 100 & NA & ---- \\
\hline Colitrimazole & NA & --- & NA & ---- & 26 & 100 \\
\hline
\end{tabular}

$\mathrm{NA} \rightarrow$ No Activity.

Table 3: Antioxidant activity of the extracts of Abutilon pannosum and compound 1 by ABTS

\begin{tabular}{|c|c|c|}
\hline $\begin{array}{c}\text { Compound / } \\
\text { Fraction }\end{array}$ & $\begin{array}{c}\text { Absorbance of } \\
\text { samples }\end{array}$ & \% Inhibition \\
\hline Control of ABTS & 0.520 & $0 \%$ \\
\hline Ascorbic-acid & 0.059 & $88.6 \%$ \\
\hline Ap C & 0.081 & $84.4 \%$ \\
\hline 1 & 0.120 & 76.8 \\
\hline Ap B & 0.212 & $59.2 \%$ \\
\hline Ap A & 0.487 & $6.3 \%$ \\
\hline
\end{tabular}

\subsubsection{Cytotoxic activity assessment}

The IC50 values against HePG2 indicated that the cytotoxicity of extracts decreased in the order: compound 1 was "very strong", (Ap C) was "strong", (Ap B) was "moderate", and (Ap A) was "weak", while against PC3 of compound 1 was "strong", (Ap B and Ap C) were "moderate", and (Ap A) was "weak", and against MCF-7 of compound $\mathbf{1}$ and (Ap C) were "strong", (Ap B) was "moderate", and (Ap A) was "noncytotoxic" (table4).

Table 4: Cytotoxic activity assessment of Abutilon pannosum extracts and compound $\mathbf{1}$ against human tumor cells HePG2, MCF-7 and PC3 $[16, \mathbf{1 7}, \mathbf{1 8}]$

- IC50( $\mu \mathrm{g} / \mathrm{ml}): 1$ - 10 (very strong). $11-20$ (strong). 21 - 50 (moderate). 51 - 100 (weak) and above 100 (non-cytotoxic). 


\begin{tabular}{|c|c|c|c|}
\hline \multirow{2}{*}{$\begin{array}{c}\text { Compound / } \\
\text { Fraction }\end{array}$} & \multicolumn{3}{|c|}{ In vitro Cytotoxicity IC50 $(\mu \mathrm{g} / \mathrm{ml}) \bullet$} \\
\cline { 2 - 4 } & HePG2 & MCF-7 & PC3 \\
\hline 5-FU & $6.6 \pm 0.24$ & $4.7 \pm 0.11$ & $9.6 \pm 0.27$ \\
\hline $\mathbf{1}$ & $8.6 \pm 0.73$ & $14.0 \pm 0.89$ & $19.8 \pm 1.13$ \\
\hline Ap C & $10.4 \pm 0.45$ & $15.3 \pm 0.77$ & $23.6 \pm 1.06$ \\
\hline Ap B & $49.5 \pm 2.34$ & $33.6 \pm 2.12$ & $22.3 \pm 0.98$ \\
\hline Ap A & $80.4 \pm 4.58$ & $>100$ & $90.7 \pm 5.47$ \\
\hline
\end{tabular}

-5-FU = 5-fluorouracil

\section{EXPERIMENTAL}

\subsection{Instrumentations}

\subsection{1 ${ }^{1} \mathrm{H}-\mathrm{NMR}$}

The NMR spectra were recorded in deuterated chloroform $\left(\mathrm{CDCl}_{3}\right)$ or Dimethyl Sulfoxide-deutrated6 (DMSO-d6) at either Faculty of Pharmacy, Benisweef University, on Bruker Avance III $400 \mathrm{MHz}$ for ${ }^{1} \mathrm{H}$ and $100 \mathrm{MHz}$ for ${ }^{13} \mathrm{C}$ (Bruker AG, Switzerland) with BBFO Smart Probe and Bruker 400 AEON Nitrogen-Free Magnet, and Topspin 3.1 software for data analysis, or at Faculty of Science, Cairo University, on Varian Mercury VX-300 NMR spectrometer, run at $300 \mathrm{MHz}$ for ${ }^{1} \mathrm{H}$ and at $75.46 \mathrm{MHz}$ for ${ }^{13} \mathrm{C}$. Chemical shifts are quoted in $\delta$ (ppm) and were related to that of the solvents.

\subsubsection{GC/MS analysis}

Method 1: GC/MS analysis was performed at the Central Laboratory of the Ministry of Agriculture, Al Bhooth Str, Cairo, on Agilent 6890 gas chromatograph equipped with an Agilent mass spectrometric column HP-5ms (30 m x $0.32 \mathrm{~mm}$ $\mathrm{x} 0.25 \mu \mathrm{m}$ film thickness). Samples were injected under the following condition: Helium was used as carrier gas at approximately $1 \mathrm{ml} / \mathrm{min}$, pulsed splitless mode. The solvent delay was $3 \mathrm{~min}$ and the injection size was $1.0 \mu 1$. The mass spectrophotometric detector was operated in electron impact ionization mode with an ionizing energy of $70 \mathrm{eV}$, scanning from $\mathrm{m} / \mathrm{z} 50$ to 500 . The ion source temperature was $230^{\circ} \mathrm{C}$ and the quadruple temperature was $150^{\circ} \mathrm{C}$. The electron multiplier voltage (EM voltage) was maintained at $1250 \mathrm{v}$ above auto tune. The instrument was manually tuned using perfluorotributyl amine (PFTBA). The GC temperature program was started at $60^{\circ} \mathrm{C}$ then elevated to $280^{\circ} \mathrm{C}$ at rate of $8^{\circ} \mathrm{C} / \mathrm{min}$. and $10 \mathrm{~min}$. hold at $280^{\circ} \mathrm{C}$ the detector and injector temperature were set at $280^{\circ} \mathrm{C}$ and $250^{\circ} \mathrm{C}$, respectively. Wiley and Nist 05 mass spectral database was used in the identification of the separated peaks.

Method 2: GC/MS analysis was performed at the National Research Center (NRC), Dokki, Cairo, and on a varian GC interfaced to Finnigan SSQ 7000 Mass Selective Detector (MSD) with ICIS V2.0 data system for MS identification of the GC components. The column used was DB-5 (J \& W Scientific, Folsom, CA) cross-linked fused silica capillary column (30 m long, $0.25 \mathrm{~mm}$ internal diameter) coated with poly dimethyl siloxane $(0.5 \mu \mathrm{m}$ film thickness $)$. The oven temperature was programmed from $50^{\circ} \mathrm{C}$ for $3 \mathrm{~min}$., at isothermal, then heating by $7^{\circ} \mathrm{C} / \mathrm{min}$. to $250^{\circ} \mathrm{C}$ and isothermally for $10 \mathrm{~min}$., at $250^{\circ} \mathrm{C}$. Injector temperature was $200^{\circ} \mathrm{C}$ and the volume injected was $0.5 \mu \mathrm{l}$. Transition-line and ion source temperature were $250^{\circ} \mathrm{C}$ and $150^{\circ} \mathrm{C}$ respectively. The mass spectrometer had a delay of
3 min. to permit the solvent plead and then scanned from $\mathrm{m} / \mathrm{z}$ 50 to $\mathrm{m} / \mathrm{z} 300$. Ionization energy was set at $70 \mathrm{ev}$.

\subsection{Materials}

\subsubsection{Plant material}

Abutilon pannosum was collected from Tennidah village, Dakhla oasis, and new valley governorate in western desert on March 2014 by Dr. Maha Elshamy, Botany Department, Faculty of Science, Mansoura University. The leaves were used for investigation.

\subsubsection{Cell line}

Hepatocellular carcinoma (liver) HePG-2, mammary gland (breast) MCF-7 and Human (prostate) cancer cell line PC3 were obtained from ATCC via Holding company for biological products and vaccines (VACSERA), Cairo, Egypt.

\subsubsection{Chemical reagents and solvents}

The reagents RPMI-1640 medium, MTT, DMSO, 5fluorouracil (Sigma co., St. Louis, USA) and Fetal Bovine serum (GIBCO, UK) were used for cytotoxicity assessment. Thin layer chromatography and preparative (TLC) were performed on silica gel (Kieselgel 60, GF 254). Silica gel (60$120 \mathrm{Mesh}$ ) for column chromatography (Nice Chemicals Co.), Lipophilic sephadex LH-20 for column was obtained from sigma chemical company, hexane was obtained from Alpha Chemika, methylene chloride was obtained from SDFCL SD fine-chem limited; EtOAc, $\mathrm{MeOH}, \mathrm{BuOH}, \mathrm{C}_{6} \mathrm{H}_{6},\left(\mathrm{CH}_{3}\right)_{2} \mathrm{CO}$ and $\mathrm{Na}_{2} \mathrm{SO}_{4}$, were obtained from Adowic.

\subsubsection{Spray reagent}

P-Anisaldehyde-sulphuric acid reagent was prepared freshly by adding conc. sulphuric acid $(8 \mu \mathrm{l})$ to solution of $\mathrm{p}$ Anisaldehyde $(0.5 \mu \mathrm{l})$ in glacial acetic acid $(10 \mu \mathrm{l})$ and methanol $(85 \mu 1)$. The chromatogram after spraying was heated at $100^{\circ} \mathrm{C}$ until the spots attained maximum color (Wagner et al., 1984).

\subsection{Processing of Abutilon pannosum leaves}

The freshly collected plant material of Abutilon pannosum was cut into small pieces and air dried in shade at room temperature. After drying the plant material, leaves were ground to give (400.21 g) of dried powdered material, and extracted by soxhlet extractor using different solvents of different polarity; petroleum ether 60-80, methylene chloride and methanol respectively to attain three fractions: petroleum ether fraction (Ap A, 10.920 g), Methylene chloride fraction (Ap B, $3.355 \mathrm{~g}$ ), and Methanol fraction (Ap C, $14.974 \mathrm{~g}$ ).The Butanol fraction (Ap D, 7.043g) separated from Methanol fraction.

\subsubsection{Processing of petroleum ether fraction} (Ap A)

A sample from Ap A fraction $(0.816 \mathrm{~g})$ was analyzed by GC/MS using method 1. Then, the fraction Ap A (10.104 g) was defatted through dissolving in cold methanol to obtain defatted part (1.752 g). A part of which (1.152 g) was subjected to column chromatography over silica gel using a series of eluents from petroleum ether / ethyl acetate combinations of 
increase polarity. Ninety-five sub fraction were collected from the column and by inspecting their TLC, five sub-fractions (14a, 17a, 78a, 85a, and 90a) were chosen to ${ }^{1} \mathrm{H}-\mathrm{NMR}$, and according to the results of ${ }^{1} \mathrm{H}-\mathrm{NMR}$, the sub fraction (14a, $0.317 \mathrm{~g}$ ) was chosen for GC/MS analysis by method 2 as (Ap a) .The remaining part $(0.513 \mathrm{~g})$ was used for biological activity.

\subsubsection{Chemical composition of fraction (Ap}

\section{A) by $G C / M S$}

petroleum ether Fraction Ap A afforded by GC/MS using method 1 n-undecane (2) $\left(\mathrm{R}_{\mathrm{t}}=9.22 \mathrm{~min}\right.$., $\left.0.55 \%\right)$, n-dodecane (3) $\left(\mathrm{R}_{\mathrm{t}}=11.18 \mathrm{~min} ., 0.57 \%\right)$, 2-methyldodecane (21) $\left(\mathrm{R}_{\mathrm{t}}=12.34\right.$ min., 0.25\%), 2,6-dimethyldodecane (24) $\left(\mathrm{R}_{\mathrm{t}}=12.49\right.$ min., $0.44 \%)$, n-tridecane (4) $\left(\mathrm{R}_{\mathrm{t}}=12.99 \min ., 01.65 \%\right)$, ntetradecane (5) $\left(\mathrm{R}_{\mathrm{t}}=14.69\right.$ min., 2.62\%), phytane (43) $\left(\mathrm{R}_{\mathrm{t}}=\right.$ 15.68 min., $1.65 \%)$, n-pentadecane (6) $\left(\mathrm{R}_{\mathrm{t}}=16.28 \mathrm{~min}\right.$., 4.79\%), n-hexadecane (7) $\left(\mathrm{R}_{\mathrm{t}}=17.78 \mathrm{~min} ., 6.54 \%\right)$, 2-methyl hexadecane (22) $\left(\mathrm{R}_{\mathrm{t}}=18.67\right.$ min., 1.97\%), n-heptadecane (8) $\left(\mathrm{R}_{\mathrm{t}}=19.20\right.$ min., 7.29\%), 1-methyl-9H-fluorine (53) $\left(\mathrm{R}_{\mathrm{t}}=19.49\right.$ min., 1.79\%), n-octadecane (9) $\left(\mathrm{R}_{\mathrm{t}}=20.55 \mathrm{~min} .\right.$, 7.31\%), 3methyloctadecane (23) $\left(\mathrm{R}_{\mathrm{t}}=21.35 \mathrm{~min} ., 3.75 \%\right)$, n-nonadecane (10) $\left(\mathrm{R}_{\mathrm{t}}=21.83 \mathrm{~min} ., 8.28 \%\right)$, n-hexadecanoic acid (25) $\left(\mathrm{R}_{\mathrm{t}}=\right.$ 22.67 min., 5.78\%), n-eicosane (11) $\left(\mathrm{R}_{\mathrm{t}}=23.05 \mathrm{~min}\right.$., $\left.7.63 \%\right)$, n-heineicosane (12) $\left(\mathrm{R}_{\mathrm{t}}=24.21\right.$ min., 5.39\%), phytol (46) $\left(\mathrm{R}_{\mathrm{t}}=\right.$ $24.41 \mathrm{~min}$., 3.09\%), methyllinolenate (31) $\left(\mathrm{R}_{\mathrm{t}}=24.76 \mathrm{~min}\right.$., $4.15 \%)$, n-docosane (13) $\left(\mathrm{R}_{\mathrm{t}}=25.33 \mathrm{~min} ., 4.69 \%\right), 14-\beta-\mathrm{H}-$ pregnane (45) $\left(\mathrm{R}_{\mathrm{t}}=25.54 \mathrm{~min}\right.$., 1.68\%), n-tricosane (14) $\left(\mathrm{R}_{\mathrm{t}}=\right.$ 26.40 min., 3.63\%), n-tetracosane (15)

$\left(\mathrm{R}_{\mathrm{t}}=27.43\right.$ min., 3.21\%), n-pentacosane (16) $\left(\mathrm{R}_{\mathrm{t}}=28.41 \mathrm{~min}\right.$., $3.34 \%)$, n-hexacosane (17) $\left(\mathrm{R}_{\mathrm{t}}=29.36\right.$ min., 1.95\%), $\mathrm{n}$ heptacosane (18) $\left(\mathrm{R}_{\mathrm{t}}=30.28\right.$ min., 1.40\%), n-octacosane (19) $\left(\mathrm{R}_{\mathrm{t}}=31.21 \mathrm{~min} ., 0.79 \%\right)$, squalene $(50)\left(\mathrm{R}_{\mathrm{t}}=31.60 \mathrm{~min}\right.$., $2.78 \%)$, n-nonacosane (20) $\left(\mathrm{R}_{\mathrm{t}}=32.27 \mathrm{~min} ., 0.70 \%\right)$ and vitamin $\mathrm{E}(51)\left(\mathrm{R}_{\mathrm{t}}=35.85\right.$ min., 0.50\%).

\subsubsection{Chemical composition of sub-fraction}

\section{(Ap a) by GC/MS}

Petroleum ether sub-fraction (Ap a) afforded by GC/MS using method 2 methyl octadeca-12,15-diynoate (30) $\left(\mathrm{R}_{\mathrm{t}}=30.93\right.$ $\min ., 2.82 \%)$, methyl octadeca-10,13-diynoate (29) $\left(\mathrm{R}_{\mathrm{t}}=32.87\right.$ $\min ., 1.61 \%)$, n-octadecane (9) $\left(\mathrm{R}_{\mathrm{t}}=36.64 \min ., 6.26 \%\right)$, $\mathrm{n}$ nonadecane (10) $\left(\mathrm{R}_{\mathrm{t}}=39.11 \mathrm{~min} ., 8.48 \%\right)$, methylpalmitate (28) $\left(\mathrm{R}_{\mathrm{t}}=\quad 39.83 \quad\right.$ min., $\left.\quad 38.98 \%\right), \quad 2-[4-m e t h y l-6-(2,6,6-$ trimethylcyclohex-1-enyl)hexa-1,3,5-trienyl]cyclohex-1-en-1carboxaldehyde (48) $\left(\mathrm{R}_{\mathrm{t}}=40.00 \mathrm{~min} ., 1.21 \%\right)$, n-eicosane (11) $\left(\mathrm{R}_{\mathrm{t}}=41.47\right.$ min., 8.28\%), n-heineicosane (12) $\left(\mathrm{R}_{\mathrm{t}}=43.76\right.$ min., $8.08 \%)$, methyllinolenate $(31)\left(\mathrm{R}_{\mathrm{t}}=43.87\right.$ min., $\left.5.65 \%\right)$, methyl stearate $(32)\left(\mathrm{R}_{\mathrm{t}}=44.42 \min\right.$., $\left.1.61 \%\right), \mathrm{n}$-docosane (13) $\left(\mathrm{R}_{\mathrm{t}}=\right.$ 45.93 min., 5.85\%), n-tricosane (14) $\left(\mathrm{R}_{\mathrm{t}}=48.02 \mathrm{~min}\right.$., 4.24\%), n-tetracosane (15) $\left(\mathrm{R}_{\mathrm{t}}=50.03\right.$ min., 3.23\%), n-pentacosane (16) $\left(\mathrm{R}_{\mathrm{t}}=51.96\right.$ min., $\left.2.22 \%\right)$ and $\mathrm{n}$-hexacosane $(17)\left(\mathrm{R}_{\mathrm{t}}=53.83\right.$ min., $1.41 \%)$.

\subsubsection{Processing of methylene chloride fraction}

\section{(Ap B)}

A sample from Ap B fraction (0.683 g) was analyzed by GC/MS using method 1, a part from it (2.005 g) was subjected to column chromatography over silica gel using a series of eluents from hexane / ethyl acetate combinations of increase polarity. Fifty-eight sub-fraction were collected from the column and by inspecting their TLC, nine sub fractions $(5 \mathrm{~b}, 7 \mathrm{~b}$, 12b, 16b, 20b, 25b, 35b, 41b and 43b) were chosen to ${ }^{1} \mathrm{H}-\mathrm{NMR}$, and according to the results of ${ }^{1} \mathrm{H}-\mathrm{NMR}$, the sub-fractions ( $5 \mathrm{~b}$, $7 \mathrm{~b}, 0.483 \mathrm{~g}$ ) were mixed together as (Ap b) and were chosen for GC/MS analysis by method 2 . The samples $(16 \mathrm{~b}, 25 \mathrm{~b})$ were mixed together and subjected to reversed phase column according to ${ }^{1} \mathrm{H}-\mathrm{NMR}$ results but no any benefit results were obtained. The remaining part $(0.497 \mathrm{~g})$ was used for biological activity.

\subsubsection{Chemical composition of fraction (Ap B) by $G C / M S$}

Methylene chloride fraction Ap B afforded by GC/MS using method 1 n-tetradecane (5) $\left(\mathrm{R}_{\mathrm{t}}=14.67\right.$ min., 0.33\%), $\mathrm{n}$ pentadecane (6) $\left(\mathrm{R}_{\mathrm{t}}=16.26 \mathrm{~min} ., 0.85 \%\right)$, dehydroxyloliolide (33) $\left(\mathrm{R}_{\mathrm{t}}=17.08 \mathrm{~min} ., 0.39 \%\right)$, n-hexadecane (7) $\left(\mathrm{R}_{\mathrm{t}}=17.75\right.$ min., $1.6 \%)$, crocetane (43) $\left(\mathrm{R}_{\mathrm{t}}=18.45 \mathrm{~min} ., 0.82 \%\right)$, 2-methyl hexadecane (22) $\left(\mathrm{R}_{\mathrm{t}}=18.65\right.$ min., 0.28\%), n-heptadecane (8) $\left(\mathrm{R}_{\mathrm{t}}=19.16\right.$ min., $\left.1.85 \%\right)$, pristine $(40)\left(\mathrm{R}_{\mathrm{t}}=19.25\right.$ min., $\left.1.36 \%\right)$, loliolide (35) $\left(\mathrm{R}_{\mathrm{t}}=20.42 \mathrm{~min}\right.$., 1.01\%), n-octadecane (9) $\left(\mathrm{R}_{\mathrm{t}}=\right.$ 20.51 min., 2.64\%), neophytadiene (42) $\left(\mathrm{R}_{\mathrm{t}}=21.04 \mathrm{~min}\right.$., $5.58 \%)$, 2,6,10-trimethyldodecane (38) $\left(\mathrm{R}_{\mathrm{t}}=21.13 \mathrm{~min}\right.$., $1.06 \%)$, n-nonadecane (10) $\left(\mathrm{R}_{\mathrm{t}}=21.79\right.$ min., $\left.2.32 \%\right)$, methyl palmitate (28) $\left(\mathrm{R}_{\mathrm{t}}=22.12\right.$ min., 1.36\%), n-hexadecanoic acid (25) $\left(\mathrm{R}_{\mathrm{t}}=22.61 \mathrm{~min} ., 4.97 \%\right)$, n-eicosane (11) $\left(\mathrm{R}_{\mathrm{t}}=23.01 \mathrm{~min}\right.$., $3.27 \%)$, n-heneicosane (12) $\left(\mathrm{R}_{\mathrm{t}}=24.18 \mathrm{~min} ., 2.73 \%\right)$, methyllinolenate (31) $\left(\mathrm{R}_{\mathrm{t}}=24.26 \mathrm{~min} ., 0.43 \%\right)$, phytol $(46)\left(\mathrm{R}_{\mathrm{t}}=\right.$ 24.39 min., 31.69\%), 9-octadecenoic acid (26) $\left(\mathrm{R}_{\mathrm{t}}=24.73\right.$ $\min ., 2.75 \%)$, n-docosane (13) $\left(\mathrm{R}_{\mathrm{t}}=25.30 \mathrm{~min} ., 2.79 \%\right)$, $\mathrm{n}$ tricosane (14) $\left(\mathrm{R}_{\mathrm{t}}=26.37 \mathrm{~min} ., 2.54 \%\right), 4,8,12,16$-tetramethyl heptadecan-1,4-olide (47) $\left(\mathrm{R}_{\mathrm{t}}=27.03 \mathrm{~min} ., 1.29 \%\right)$, geranyl acetone (34) $\left(\mathrm{R}_{\mathrm{t}}=27.33\right.$ min., 0.55\%), n-tetracosane $(15)\left(\mathrm{R}_{\mathrm{t}}=\right.$ 27.40 min., 3.04\%), n-pentacosane (16) $\left(\mathrm{R}_{\mathrm{t}}=28.39 \mathrm{~min}\right.$., $2.24 \%)$, squalene (50) $\left(\mathrm{R}_{\mathrm{t}}=31.58 \mathrm{~min} ., 15.76 \%\right)$, vitamin $\mathrm{E}(51)$ $\left(\mathrm{R}_{\mathrm{t}}=35.58 \mathrm{~min} ., 3.00 \%\right)$ and gibberellin $\mathrm{A} 3(49)\left(\mathrm{R}_{\mathrm{t}}=38.41\right.$ $\min ., 1.31 \%)$.

\subsubsection{Chemical composition of sub-fraction} (Ap b) by GC/MS

Methylene chloride-sub fraction (Ap b) afforded by GC/MS using method 2 4(15),6-cadinadiene (37) ( $\mathrm{Rt}=24.46 \mathrm{~min}$., $1.76 \%)$, trans- $\beta$-caryophyllene (36) $\left(\mathrm{R}_{\mathrm{t}}=25.83 \mathrm{~min}\right.$., $\left.5.67 \%\right)$, nhexadecane (7) $\left(\mathrm{R}_{\mathrm{t}}=27.13 \mathrm{~min} ., 4.44 \%\right)$, phytol (46) $\left(\mathrm{R}_{\mathrm{t}}=37.57\right.$ min., 1.82\%), 6,10,14-trimethyl-2-pentadecanone (41) $\left(\mathrm{R}_{\mathrm{t}}=\right.$ 37.75 min., 13.27\%), methyl 14-methylpentadecanoate (27) $\left(\mathrm{R}_{\mathrm{t}}=39.91 \mathrm{~min} ., 4.63 \%\right)$, dioctyladipate $(54)\left(\mathrm{R}_{\mathrm{t}}=50.11 \mathrm{~min}\right.$., $4.88 \%)$, squalene (50) $\left(\mathrm{R}_{\mathrm{t}}=57.94 \mathrm{~min} ., 61.71 \%\right)$ and 3,4,3',4'tetrahydrospirilloxanthin (52) $\left(\mathrm{R}_{\mathrm{t}}=60.99 \mathrm{~min} ., 1.76 \%\right)$.

\subsubsection{Processing of methanol fraction $(A p C)$}

Methanol fraction (Ap C, $13.651 \mathrm{~g}$ ) was portioned between water and butanol in separating funnel. The butanol layer was evaporated to dryness affording (ApD, $7.043 \mathrm{~g}$ ). A sample from (ApD, $3.907 \mathrm{~g}$ ) was subjected to silica gel column using methanol / methylene chloride eluents of increase polarity. The 
sub-fractions were subjected to sephadex LH-20 column using methanol solvent as eluent, followed by TLC purification with eluent system ethyl acetate $(9.1 \mathrm{ml})$ / methanol $(0.6 \mathrm{ml})$ / water $(0.3 \mathrm{ml})$ to give $\mathbf{1}\left(594 \mathrm{mg}, \mathrm{R}_{\mathrm{f}}=0.65\right)$.

\subsection{Biological applications}

\subsubsection{Antimicrobial activity assessment}

The three fractions and the isolated compound were individually tested against a panel of gram positive (Staphylococcus aureus), gram negative (Escherichia coli) bacterial and the fungus (Candida albicans). Each of the fractions and the isolated compound was dissolved in DMSO and solution of the concentration $1 \mathrm{mg} / \mathrm{ml}$ were prepared separately. Paper discs of Whatman filter paper were prepared with standard size (5 $\mathrm{mm}$ diameter), were cut and sterilized in an autoclave. The paper discs were soaked in the desired concentration of the extract solution and placed aseptically in the Petri-dishes containing nutrient agar media (agar $20 \mathrm{~g}+$ beef extract $3 \mathrm{~g}+$ peptone $5 \mathrm{~g}$ ) seeded with Staphylococcus aureus, Escherichia coli and Candida albicans. The Petri dishes were incubated at $36^{\circ} \mathrm{C}$ and the inhibition zones were recorded after one day of incubation. Each treatment was replicate 3 times. The antibacterial activities of a common standard antibiotics ampicillin, gentamicin and amphotericin $B$ were also recorded using the same procedure as above at the same concentration and solvents. The \% activity index for each treatment was calculated by the formula:

$\%$ Activity Index

$=\frac{\text { Zone of inhibition by test extract (diametre) }}{\text { Zone of inhibition by standard (diametre) }} \times 100$

Table 5: The MS data of compounds identified by GC/MS

\begin{tabular}{|c|c|c|}
\hline \multicolumn{2}{|c|}{ Compound name and number } & MS Data $: m / z$ [identity](rel. abound.\%) \\
\hline 2 & n-undecane & $\begin{array}{l}156\left[\mathrm{M}^{+}\right](5.0 \%), 127\left[\mathrm{M}-\mathrm{C}_{2} \mathrm{H}_{5}\right]^{+}(1.7 \%), 113\left[\mathrm{M}-\mathrm{C}_{3} \mathrm{H}_{7}\right]^{+}(3.3 \%), 99\left[\mathrm{M}-\mathrm{C}_{4} \mathrm{H}_{9}\right]^{+}(6.6 \%), 85[\mathrm{M}- \\
\left.\mathrm{C}_{5} \mathrm{H}_{11}\right]^{+}(33.3 \%), 71\left[\mathrm{M}-\mathrm{C}_{6} \mathrm{H}_{13}\right]^{+}(53.3 \%), 57\left[\mathrm{M}-\mathrm{C}_{7} \mathrm{H}_{15}\right]^{+}(100 \%)\end{array}$ \\
\hline 3 & n-dodecane & $\begin{array}{l}170\left[\mathrm{M}^{+}\right](5.0 \%), 141\left[\mathrm{M}-\mathrm{C}_{2} \mathrm{H}_{5}\right]^{+}(1.0 \%), 127\left[\mathrm{M}-\mathrm{C}_{3} \mathrm{H}_{7}\right]^{+}(1.7 \%), 113\left[\mathrm{M}-\mathrm{C}{ }_{4} \mathrm{H}_{9}\right]^{+}(4.0 \%), 99[\mathrm{M}- \\
\left.\mathrm{C}_{5} \mathrm{H}_{11}\right]^{+}(6.7 \%), 85\left[\mathrm{M}-\mathrm{C}_{6} \mathrm{H}_{13}\right]^{+}(37.3 \%), 71\left[\mathrm{M}-\mathrm{C}_{7} \mathrm{H}_{15}\right]^{+}(60.0 \%), 57\left[\mathrm{M}-\mathrm{C}_{8} \mathrm{H}_{17}\right]^{+}(100 \%)\end{array}$ \\
\hline 4 & n-tridecane & 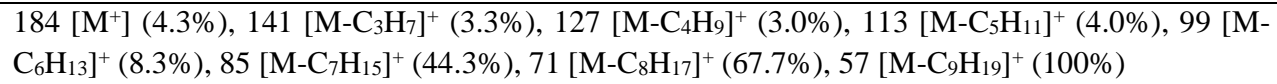 \\
\hline 5 & n-tetradecane & $\begin{array}{l}198\left[\mathrm{M}^{+}\right](3.3 \%), 173(0.3 \%), 160(1.3 \%), 145(3.3 \%), 127\left[\mathrm{M}-\mathrm{C}_{5} \mathrm{H}_{11}\right]^{+}(3.3 \%), 113\left[\mathrm{M}-\mathrm{C}_{6} \mathrm{H}_{13}\right]^{+} \\
(5.0 \%), 99\left[\mathrm{M}-\mathrm{C}_{7} \mathrm{H}_{15}\right]^{+}(10.3 \%), 85\left[\mathrm{M}-\mathrm{C}_{8} \mathrm{H}_{17}\right]^{+}(50.0 \%), 71\left[\mathrm{M}-\mathrm{C}_{9} \mathrm{H}_{19}\right]^{+}(70.7 \%), 57\left[\mathrm{M}-\mathrm{C}_{10} \mathrm{H}_{21}\right]^{+} \\
(100 \%)\end{array}$ \\
\hline 6 & n-pentadecane & $\begin{array}{l}212\left[\mathrm{M}^{+}\right](4.0 \%), 183\left[\mathrm{M}-\mathrm{C}_{2} \mathrm{H}_{5}\right]^{+}(0.7 \%), 169\left[\mathrm{M}-\mathrm{C}_{3} \mathrm{H}_{7}\right]^{+}(1.0 \%), 155\left[\mathrm{M}-\mathrm{C}_{4} \mathrm{H}_{9}\right]^{+}(2.7 \%), 141[\mathrm{M}- \\
\left.\mathrm{C}_{5} \mathrm{H}_{11}\right]^{+}(3.3 \%), 127\left[\mathrm{M}-\mathrm{C}_{6} \mathrm{H}_{13}\right]^{+}(4.0 \%), 113\left[\mathrm{M}-\mathrm{C}_{7} \mathrm{H}_{15}\right]^{+}(6.7 \%), 99\left[\mathrm{M}-\mathrm{C}_{8} \mathrm{H}_{17}\right]^{+}(13.3 \%), 85[\mathrm{M}- \\
\left.\mathrm{C}_{9} \mathrm{H}_{19}\right]^{+}(52.3 \%), 71\left[\mathrm{M}-\mathrm{C}_{10} \mathrm{H}_{21}\right]^{+}(73.3 \%), 57\left[\mathrm{M}-\mathrm{C}_{11} \mathrm{H}_{23}\right]^{+}(100 \%)\end{array}$ \\
\hline 7 & n-hexadecane & $\begin{array}{l}226\left[\mathrm{M}^{+}\right](3.3 \%), 197\left[\mathrm{M}-\mathrm{C}_{2} \mathrm{H}_{5}\right]^{+}(0.3 \%), 182(3.7 \%), 170(13.3 \%), 155\left[\mathrm{M}-\mathrm{C}_{5} \mathrm{H}_{11}\right]^{+}(16.7 \%), 141 \\
{\left[\mathrm{M}_{-} \mathrm{C}_{6} \mathrm{H}_{13}\right]^{+}(4.0 \%), 127\left[\mathrm{M}-\mathrm{C}_{7} \mathrm{H}_{15}\right]^{+}(6.7 \%), 113\left[\mathrm{M}-\mathrm{C}_{8} \mathrm{H}_{17}\right]^{+}(9.3 \%), 99\left[\mathrm{M}-\mathrm{C}_{9} \mathrm{H}_{19}\right]^{+}(16.7 \%), 85[\mathrm{M}-} \\
\left.\mathrm{C}_{10} \mathrm{H}_{21}\right]^{+}(52.3 \%), 71\left[\mathrm{M}-\mathrm{C}_{11} \mathrm{H}_{23}\right]^{+}(76.7 \%), 57\left[\mathrm{M}-\mathrm{C}_{12} \mathrm{H}_{25}\right]^{+}(100 \%)\end{array}$ \\
\hline 8 & n-heptadecane & $\begin{array}{l}240\left[\mathrm{M}^{+}\right](3.3 \%), 197\left[\mathrm{M}-\mathrm{C}_{3} \mathrm{H} 7\right]^{+}(3.3 \%), 185\left[\mathrm{M}-\mathrm{C}_{4} \mathrm{H}_{9}\right]^{+}(3.3 \%), 169\left[\mathrm{M}-\mathrm{C}_{5} \mathrm{H}_{11}\right]^{+}(6.7 \%), 141[\mathrm{M}- \\
\left.\mathrm{C}_{7} \mathrm{H}_{15}\right]^{+}(6.0 \%), 127\left[\mathrm{M}-\mathrm{C}_{8} \mathrm{H}_{17}\right]^{+}(6.7 \%), 99\left[\mathrm{M}-\mathrm{C}_{10} \mathrm{H}_{21}\right]^{+}(16.7 \%), 85\left[\mathrm{M}-\mathrm{C}_{11} \mathrm{H}_{23}\right]^{+}(60.0 \%), 71[\mathrm{M}- \\
\left.\mathrm{C}_{12} \mathrm{H}_{25}\right]^{+}(80.0 \%), 57\left[\mathrm{M}-\mathrm{C}_{13} \mathrm{H}_{27}\right]^{+}(100 \%)\end{array}$ \\
\hline 9 & n-octadecane & $\begin{array}{l}254\left[\mathrm{M}^{+}\right](3.3 \%), 211\left[\mathrm{M}-\mathrm{C}_{3} \mathrm{H}_{7}\right]^{+}(0.7 \%), 178(6.7 \%), 155\left[\mathrm{M}-\mathrm{C}_{7} \mathrm{H}_{15}\right]^{+}(3.3 \%), 141\left[\mathrm{M}-\mathrm{C}_{8} \mathrm{H}_{17}\right]^{+} \\
(4.7 \%), 127\left[\mathrm{M}-\mathrm{C}_{9} \mathrm{H}_{19}\right]^{+}(6.7 \%), 113\left[\mathrm{M}-\mathrm{C}_{10} \mathrm{H}_{21}\right]^{+}(10.7 \%), 99\left[\mathrm{M}-\mathrm{C}_{11} \mathrm{H}_{23}\right]^{+}(18.7 \%), 85\left[\mathrm{M}-\mathrm{C}_{12} \mathrm{H}_{25}\right]^{+} \\
(60.0 \%), 71\left[\mathrm{M}-\mathrm{C}_{13} \mathrm{H}_{27}\right]^{+}(80.0 \%), 57\left[\mathrm{M}-\mathrm{C}_{14} \mathrm{H}_{29}\right]^{+}(100 \%)\end{array}$ \\
\hline 10 & n-nonadecane & 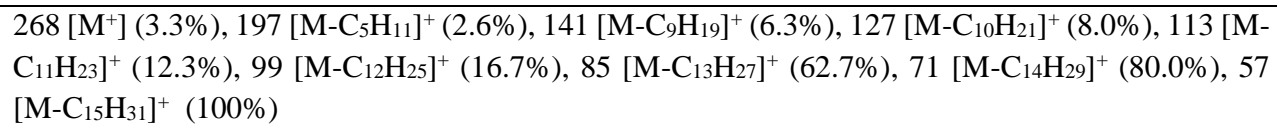 \\
\hline 11 & n-eicosane & $\begin{array}{l}282\left[\mathrm{M}^{+}\right](3.3 \%), 197\left[\mathrm{M}-\mathrm{C}_{6} \mathrm{H}_{13}\right]^{+}(3.3 \%), 155\left[\mathrm{M}-\mathrm{C}_{9} \mathrm{H}_{19}\right]^{+}(4.0 \%), 141\left[\mathrm{M}-\mathrm{C}_{10} \mathrm{H}_{21}\right]^{+}(6.7 \%), 127[\mathrm{M}- \\
\left.\mathrm{C}_{11} \mathrm{H}_{23}\right]^{+}(9.3 \%), 113\left[\mathrm{M}-\mathrm{C}_{12} \mathrm{H}_{25}\right]^{+}(13.0 \%), 99\left[\mathrm{M}-\mathrm{C}_{13} \mathrm{H}_{27}\right]^{+}(20.0 \%), 85\left[\mathrm{M}-\mathrm{C}_{14} \mathrm{H}_{29}\right]^{+}(64.0 \%), 71 \\
{\left[\mathrm{M}-\mathrm{C}_{15} \mathrm{H}_{31}\right]^{+}(80.3 \%), 57\left[\mathrm{M}-\mathrm{C}_{16} \mathrm{H}_{33}\right]^{+}(100 \%)}\end{array}$ \\
\hline 12 & n-heineicosane & 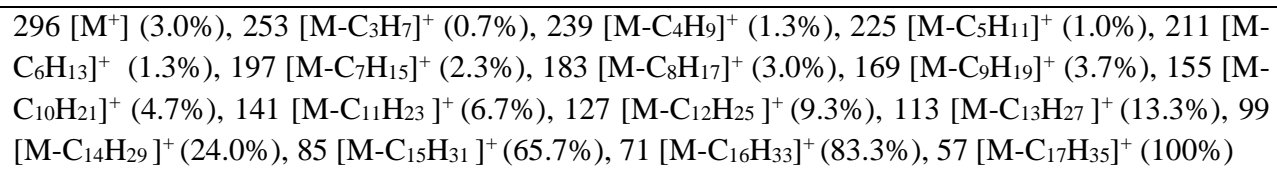 \\
\hline 13 & n-docosane & $\begin{array}{l}310\left[\mathrm{M}^{+}\right](1.3 \%), 288(0.3 \%), 253\left[\mathrm{M}-\mathrm{C}_{4} \mathrm{H}_{9}\right]^{+}(0.7 \%), 225\left[\mathrm{M}-\mathrm{C}_{6} \mathrm{H}_{13}\right]^{+}(0.7 \%), 211\left[\mathrm{M}-\mathrm{C}_{7} \mathrm{H}_{15}\right]^{+} \\
(0.7 \%), 183\left[\mathrm{M}-\mathrm{C}_{9} \mathrm{H}_{19}\right]^{+}(3.3 \%), 155\left[\mathrm{M}-\mathrm{C}_{11} \mathrm{H}_{23}\right]^{+}(4.7 \%), 127\left[\mathrm{M}-\mathrm{C}_{13} \mathrm{H}_{27}\right]^{+}(10.0 \%), 113\left[\mathrm{M}-\mathrm{C}_{14} \mathrm{H}_{29}\right. \\
]^{+}(13.3 \%), 99\left[\mathrm{M}-\mathrm{C}_{15} \mathrm{H}_{31}\right]^{+}(21.7 \%), 85\left[\mathrm{M}-\mathrm{C}_{16} \mathrm{H}_{33}\right]^{+}(83.3 \%), 71\left[\mathrm{M}-\mathrm{C}_{17} \mathrm{H}_{35}\right]^{+}(83.0 \%), 57[\mathrm{M}- \\
\left.\mathrm{C}_{18} \mathrm{H}_{37}\right]^{+}(100 \%)\end{array}$ \\
\hline
\end{tabular}


International Journal of Science and Engineering Applications

Volume 6 Issue 03, 2017, ISSN-2319-7560 (Online)

\begin{tabular}{|c|c|c|}
\hline 14 & n-tricosane & 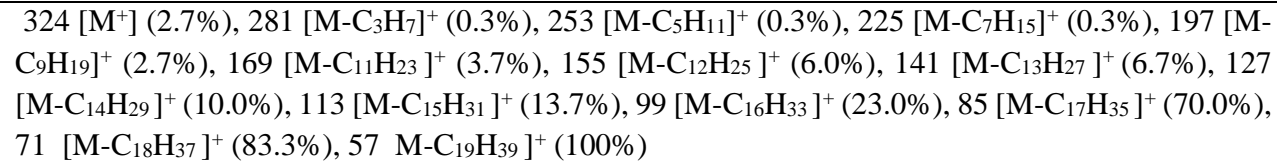 \\
\hline 15 & n-tetracosane & $\begin{array}{l}338\left[\mathrm{M}^{+}\right](1.3 \%), 281\left[\mathrm{M}-\mathrm{C}_{4} \mathrm{H}_{9}\right]^{+}(0.7 \%), 253\left[\mathrm{M}-\mathrm{C}_{6} \mathrm{H}_{13}\right]^{+}(0.7 \%), 225\left[\mathrm{M}-\mathrm{C}_{8} \mathrm{H}_{17}\right]^{+}(0.7 \%), 197[\mathrm{M}- \\
\left.\mathrm{C}_{10} \mathrm{H}_{21}\right]^{+}(3.0 \%), 169\left[\mathrm{M}-\mathrm{C}_{12} \mathrm{H}_{25}\right]^{+}(3.7 \%), 155\left[\mathrm{M}-\mathrm{C}_{13} \mathrm{H}_{27}\right]^{+}(6.3 \%), 141\left[\mathrm{M}-\mathrm{C}_{14} \mathrm{H}_{29}\right]^{+}(7.0 \%), 127 \\
{\left[\mathrm{M}-\mathrm{C}_{15} \mathrm{H}_{31}\right]^{+}(10.3 \%), 113\left[\mathrm{M}-\mathrm{C}_{16} \mathrm{H}_{33}\right]^{+}(14.0 \%), 99\left[\mathrm{M}-\mathrm{C}_{17} \mathrm{H}_{35}\right]^{+}(23.0 \%), 85\left[\mathrm{M}-\mathrm{C}_{18} \mathrm{H}_{37}\right]^{+}(70.0 \%),} \\
\left.\left.71 \mathrm{M}-\mathrm{C}_{19} \mathrm{H}_{39}\right]^{+}(83.3 \%), 57 \mathrm{M}-\mathrm{C}_{20} \mathrm{H}_{41}\right]^{+}(100 \%)\end{array}$ \\
\hline 16 & n-pentacosane & $\begin{array}{l}352\left[\mathrm{M}^{+}\right](1.0 \%), 323\left[\mathrm{M}-\mathrm{C}_{2} \mathrm{H}_{5}\right]^{+}(0.3 \%), 281\left[\mathrm{M}-\mathrm{C}_{5} \mathrm{H}_{11}\right]^{+}(0.7 \%), 253\left[\mathrm{M}-\mathrm{C}_{7} \mathrm{H}_{15}\right]^{+}(0.7 \%), 225[\mathrm{M}- \\
\left.\mathrm{C}_{9} \mathrm{H}_{19}\right]^{+}(0.7 \%), 197\left[\mathrm{M}-\mathrm{C}_{11} \mathrm{H}_{23}\right]^{+}(3.0 \%), 169\left[\mathrm{M}-\mathrm{C}_{13} \mathrm{H}_{27}\right]^{+}(3.7 \%), 155\left[\mathrm{M}-\mathrm{C}_{14} \mathrm{H}_{29}\right]^{+}(6.3 \%), 141 \\
{\left[\mathrm{M}-\mathrm{C}_{15} \mathrm{H}_{31}\right]^{+}(7.0 \%), 127\left[\mathrm{M}-\mathrm{C}_{16} \mathrm{H}_{33}\right]^{+}(10.3 \%), 113\left[\mathrm{M}-\mathrm{C}_{17} \mathrm{H}_{35}\right]^{+}(14.0 \%), 99\left[\mathrm{M}-\mathrm{C}_{18} \mathrm{H}_{37}\right]^{+}(23.0 \%),} \\
\left.85\left[\mathrm{M}-\mathrm{C}_{19} \mathrm{H}_{39}\right]^{+}(70.0 \%), 71\left[\mathrm{M}-\mathrm{C}_{20} \mathrm{H}_{41}\right]^{+}(83.3 \%), 57 \mathrm{M}-\mathrm{C}_{21} \mathrm{H}_{43}\right]^{+}(100 \%)\end{array}$ \\
\hline 17 & n-hexacosane & $\begin{array}{l}366\left[\mathrm{M}^{+}\right](0.7 \%), 309\left[\mathrm{M}-\mathrm{C}_{5} \mathrm{H}_{11}\right]^{+}(0.3 \%), 281\left[\mathrm{M}-\mathrm{C}_{6} \mathrm{H}_{13}\right]^{+}(2.7 \%), 253\left[\mathrm{M}-\mathrm{C}_{7} \mathrm{H}_{15}\right]^{+}(2.7 \%), 225[\mathrm{M}- \\
\left.\mathrm{C}_{10} \mathrm{H}_{21}\right]^{+}(2.7 \%), 197\left[\mathrm{M}-\mathrm{C}_{12} \mathrm{H}_{25}\right]^{+}(3.0 \%), 169\left[\mathrm{M}-\mathrm{C}_{14} \mathrm{H}_{29}\right]^{+}(4.0 \%), 141\left[\mathrm{M}-\mathrm{C}_{16} \mathrm{H}_{33}\right]^{+}(7.0 \%), 127 \\
{\left[\mathrm{M}-\mathrm{C}_{17} \mathrm{H}_{35}\right]^{+}(10.3 \%), 113\left[\mathrm{M}-\mathrm{C}_{18} \mathrm{H}_{37}\right]^{+}(14.0 \%), 99\left[\mathrm{M}-\mathrm{C}_{19} \mathrm{H}_{39}\right]^{+}(23.3 \%), 85\left[\mathrm{M}-\mathrm{C}_{20} \mathrm{H}_{41}\right]^{+}(66.7 \%),} \\
71\left[\mathrm{M}-\mathrm{C}_{21} \mathrm{H}_{43}\right]^{+}(83.3 \%), 57\left[\mathrm{M}-\mathrm{C}_{22} \mathrm{H}_{45}\right]^{+}(100 \%)\end{array}$ \\
\hline 18 & n-heptacosane & $\begin{array}{l}380[\mathrm{M}+](0.7 \%), 337\left[\mathrm{M}-\mathrm{C}_{3} \mathrm{H}_{7}\right]^{+}(0.3 \%), 323\left[\mathrm{M}-\mathrm{C}_{4} \mathrm{H}_{9}\right]^{+}(0.3 \%), 295\left[\mathrm{M}-\mathrm{C}_{6} \mathrm{H}_{13}\right]^{+}, 281\left[\mathrm{M}-\mathrm{C}_{7} \mathrm{H}_{15}\right]^{+} \\
(3.0 \%), 267\left[\mathrm{M}-\mathrm{C}_{8} \mathrm{H}_{17}\right]^{+}(0.4 \%), 225\left[\mathrm{M}-\mathrm{C}_{11} \mathrm{H}_{23}\right]^{+}(1.3 \%), 211\left[\mathrm{M}-\mathrm{C}_{12} \mathrm{H}_{25}\right]^{+}(3.3 \%), 197\left[\mathrm{M}-\mathrm{C}_{13} \mathrm{H}_{27}\right]^{+} \\
(3.3 \%), 169\left[\mathrm{M}-\mathrm{C}_{15} \mathrm{H}_{31}\right]^{+}(4.3 \%), 141\left[\mathrm{M}-\mathrm{C}_{17} \mathrm{H}_{35}\right]^{+}(7.0 \%), 113\left[\mathrm{M}-\mathrm{C}_{19} \mathrm{H}_{39}\right]^{+}(14.7 \%), 99\left[\mathrm{M}-\mathrm{C}_{20} \mathrm{H}_{41}\right. \\
]^{+}(23.3 \%), 85\left[\mathrm{M}-\mathrm{C}_{21} \mathrm{H}_{43}\right]^{+}(64.7 \%), 71\left[\mathrm{M}-\mathrm{C}_{22} \mathrm{H}_{45}\right]^{+}(82.7 \%), 57\left[\mathrm{M}-\mathrm{C}_{23} \mathrm{H}_{47}\right]^{+}(100 \%)\end{array}$ \\
\hline 19 & n-octacosane & $\begin{array}{l}394\left[\mathrm{M}^{+}\right](0.3 \%), 355(0.3 \%), 309\left[\mathrm{M}-\mathrm{C}_{6} \mathrm{H}_{13}\right]^{+}(0.7 \%), 281\left[\mathrm{M}-\mathrm{C}_{8} \mathrm{H}_{17}\right]^{+}(6.3 \%), 253\left[\mathrm{M}-\mathrm{C}_{10} \mathrm{H}_{21}\right]^{+} \\
(3.0 \%), 225\left[\mathrm{M}-\mathrm{C}_{12} \mathrm{H}_{25}\right]^{+}(2.7 \%), 207\left[\mathrm{M}-\mathrm{C}_{14} \mathrm{H}_{19}\right]^{+}(13.0 \%), 169\left[\mathrm{M}-\mathrm{C}_{16} \mathrm{H}_{33}\right]^{+}(4.3 \%), 141\left[\mathrm{M}-\mathrm{C}_{18} \mathrm{H}_{37}\right. \\
]^{+}(7.0 \%), 127\left[\mathrm{M}-\mathrm{C}_{19} \mathrm{H}_{39}\right]^{+}(10.3 \%), 113\left[\mathrm{M}-\mathrm{C}_{20} \mathrm{H}_{41}\right]^{+}(14.3 \%), 99\left[\mathrm{M}-\mathrm{C}_{21} \mathrm{H}_{43}\right]^{+}(23.3 \%), 85[\mathrm{M}- \\
\left.\mathrm{C}_{22} \mathrm{H}_{45}\right]^{+}(63.3 \%), 71\left[\mathrm{M}-\mathrm{C}_{23} \mathrm{H}_{47}\right]^{+}(80.3 \%), 57\left[\mathrm{M}-\mathrm{C}_{24} \mathrm{H}_{49}\right]^{+}(100 \%)\end{array}$ \\
\hline 20 & n-nonacosane & $\begin{array}{l}408\left[\mathrm{M}^{+}\right](0.3 \%), 355(0.7 \%), 309\left[\mathrm{M}-\mathrm{C}_{7} \mathrm{H}_{15}\right]^{+}(0.7 \%), 281\left[\mathrm{M}-\mathrm{C}_{9} \mathrm{H}_{19}\right]^{+}(6.3 \%), 253\left[\mathrm{M}_{-} \mathrm{C}_{11} \mathrm{H}_{23}\right]^{+} \\
(3.0 \%), 225\left[\mathrm{M}-\mathrm{C}_{13} \mathrm{H}_{27}\right]^{+}(0.7 \%), 207\left[\mathrm{M}-\mathrm{C}_{15} \mathrm{H}_{21}\right]^{+}(10.7 \%), 169\left[\mathrm{M}-\mathrm{C}_{17} \mathrm{H}_{35}\right]^{+}(3.7 \%), 141\left[\mathrm{M}-\mathrm{C}_{19} \mathrm{H}_{39}\right. \\
]^{+}(8.3 \%), 127\left[\mathrm{M}-\mathrm{C}_{20} \mathrm{H}_{41}\right]^{+}(11.0 \%), 113\left[\mathrm{M}-\mathrm{C}_{21} \mathrm{H}_{43}\right]^{+}(16.0 \%), 99\left[\mathrm{M}-\mathrm{C}_{22} \mathrm{H}_{45}\right]^{+}(23.3 \%), 85[\mathrm{M}- \\
\left.\mathrm{C}_{23} \mathrm{H}_{47}\right]^{+}(64.3 \%), 71\left[\mathrm{M}-\mathrm{C}_{24} \mathrm{H}_{49}\right]^{+}(83.3 \%), 57\left[\mathrm{M}-\mathrm{C}_{25} \mathrm{H}_{51}\right]^{+}(100 \%)\end{array}$ \\
\hline 21 & 2-methyldodecane & $\begin{array}{l}184\left[\mathrm{M}^{+}\right](0.3 \%), 169\left[\mathrm{M}-\mathrm{CH}_{3}\right]^{+}(6.7 \%), 141\left[\mathrm{M}-\mathrm{C}_{3} \mathrm{H}_{7}\right]^{+}(13.5 \%), 127\left[\mathrm{M}-\mathrm{C}_{4} \mathrm{H}_{9}\right]^{+}(3.3 \%), 113[\mathrm{M}- \\
\left.\mathrm{C}_{5} \mathrm{H}_{11}\right]^{+}(8.3 \%), 99\left[\mathrm{M}-\mathrm{C}_{6} \mathrm{H}_{13}\right]^{+}(19.7 \%), 85\left[\mathrm{M}-\mathrm{C}_{7} \mathrm{H}_{15}\right]^{+}(60.0 \%), 71\left[\mathrm{M}-\mathrm{C}_{8} \mathrm{H}_{17}\right]^{+}(76.7 \%), 57[\mathrm{M}- \\
\left.\mathrm{C}_{9} \mathrm{H}_{19}\right]^{+}(100 \%)\end{array}$ \\
\hline 22 & 2-methylhexadecane & $\begin{array}{l}240\left[\mathrm{M}^{+}\right](0.2 \%), 225\left[\mathrm{M}-\mathrm{CH}_{3}\right]^{+}(4.7 \%), 197\left[\mathrm{M}-\mathrm{C}_{3} \mathrm{H}_{7}\right]^{+}(13.3 \%), 184\left[\mathrm{M}-\mathrm{C}_{4} \mathrm{H}_{8}\right]^{+}(10.0 \%), 169[\mathrm{M}- \\
\left.\mathrm{C}_{5} \mathrm{H}_{11}\right]^{+}(8.3 \%), 155\left[\mathrm{M}-\mathrm{C}_{6} \mathrm{H}_{13}\right]^{+}(13.3 \%), 141\left[\mathrm{M}-\mathrm{C}_{7} \mathrm{H}_{15}\right]^{+}(10.0 \%), 127\left[\mathrm{M}-\mathrm{C}_{8} \mathrm{H}_{17}\right]^{+}(13.3 \%), 113 \\
{\left[\mathrm{M}-\mathrm{C}_{9} \mathrm{H}_{19}\right]^{+}(16.7 \%), 99\left[\mathrm{M}-\mathrm{C}_{10} \mathrm{H}_{21}\right]^{+}(22.7 \%), 85\left[\mathrm{M}-\mathrm{C}_{11} \mathrm{H}_{23}\right]^{+}(54.3 \%), 71\left[\mathrm{M}-\mathrm{C}_{12} \mathrm{H}_{25}\right]^{+}(64.3 \%), 57} \\
{\left[\mathrm{M}-\mathrm{C}_{13} \mathrm{H}_{27}\right]^{+}(100 \%)}\end{array}$ \\
\hline 23 & 3-methyloctadecane & $\begin{array}{l}268\left[\mathrm{M}^{+}\right](0.3 \%), 253\left[\mathrm{M}-\mathrm{CH}_{3}\right]^{+}(3.3 \%), 239\left[\mathrm{M}-\mathrm{C}_{2} \mathrm{H}_{5}\right]^{+}(1.0 \%), 211\left[\mathrm{M}-\mathrm{C}_{4} \mathrm{H}_{9}\right]^{+}(3.3 \%), 197[\mathrm{M}- \\
\left.\mathrm{C}_{5} \mathrm{H}_{11}\right]^{+}(4.0 \%), 183\left[\mathrm{M}-\mathrm{C}_{6} \mathrm{H}_{13}\right]^{+}(7.7 \%), 169\left[\mathrm{M}-\mathrm{C}_{7} \mathrm{H}_{15}\right]^{+}(11.3 \%), 155\left[\mathrm{M}-\mathrm{C}_{8} \mathrm{H}_{17}\right]^{+}(10.0 \%), 141 \\
{\left[\mathrm{M}-\mathrm{C}_{9} \mathrm{H}_{19}\right]^{+}(10.7 \%), 127\left[\mathrm{M}-\mathrm{C}_{10} \mathrm{H}_{21}\right]^{+}(11.0 \%), 113\left[\mathrm{M}-\mathrm{C}_{11} \mathrm{H}_{23}\right]^{+}(13.3 \%), 99\left[\mathrm{M}-\mathrm{C}_{12} \mathrm{H}_{25}\right]^{+}(21.7 \%),} \\
85\left[\mathrm{M}-\mathrm{C}_{13} \mathrm{H}_{27}\right]^{+}(56.0 \%), 71\left[\mathrm{M}-\mathrm{C}_{14} \mathrm{H}_{29}\right]^{+}(70.7 \%), 57\left[\mathrm{M}-\mathrm{C}_{15} \mathrm{H}_{31}\right]^{+}(100 \%)\end{array}$ \\
\hline 24 & 2,6-dimethyldodecane & $\begin{array}{l}198\left[\mathrm{M}^{+}\right](0.75 \%), 183\left[\mathrm{M}-\mathrm{CH}_{3}\right]^{+}(0.2 \%), 155\left[\mathrm{M}-\mathrm{C}_{3} \mathrm{H}_{7}\right]^{+}(1.3 \%), 141\left[\mathrm{M}-\mathrm{C}_{4} \mathrm{H}_{9}\right]^{+}(1.0 \%), 127[\mathrm{M}- \\
\left.\mathrm{C}_{5} \mathrm{H}_{11}\right]^{+}(2.7 \%), 113\left[\mathrm{M}-\mathrm{C}_{6} \mathrm{H}_{13}\right]^{+}(16.7 \%), 85\left[\mathrm{M}-\mathrm{C}_{7} \mathrm{H}_{15}\right]^{+}(14.3 \%), 71\left[\mathrm{M}-\mathrm{C}_{9} \mathrm{H}_{19}\right]^{+}(92.7 \%), 57 \\
(100 \%)\end{array}$ \\
\hline 25 & n-hexadecanoic acid & $\begin{array}{l}256\left[\mathrm{M}^{+}\right](29.3 \%), 241\left[\mathrm{M}-\mathrm{CH}_{3}\right]^{+}(0.7 \%), 227\left[\mathrm{M}-\mathrm{C}_{2} \mathrm{H}_{5}\right]^{+}(9.0 \%), 213\left[\mathrm{M}-\mathrm{C}_{3} \mathrm{H}_{7}\right]^{+}(10.5 \%), 199[\mathrm{M}- \\
\left.\mathrm{C}_{4} \mathrm{H}_{7}\right]^{+}(10.0 \%), 185\left[\mathrm{M}-\mathrm{C}_{5} \mathrm{H}_{11}\right]^{+}(21.3 \%), 171\left[\mathrm{M}-\mathrm{C}_{6} \mathrm{H}_{13}\right]^{+}(21.0 \%), 157\left[\mathrm{M}-\mathrm{C}_{7} \mathrm{H}_{15}\right]^{+}(23.3 \%), 143 \\
{\left[\mathrm{M}-\mathrm{C}_{8} \mathrm{H}_{17}\right]^{+}(11.3 \%), 139\left[\mathrm{M}-\mathrm{C}_{4} \mathrm{H}_{9}\right\}^{+}(3.3 \%), 129\left[\mathrm{M}-\mathrm{C}_{9} \mathrm{H}_{19}\right]^{+}(56.7 \%), 115\left[\mathrm{M}-\mathrm{C}_{10} \mathrm{H}_{21}\right]^{+}(22.7 \%), 97} \\
{\left[\mathrm{M}-\mathrm{C}_{7} \mathrm{H}_{15}\right]^{+}(37.0 \%), 85\left[\mathrm{M}-\mathrm{C}_{8} \mathrm{H}_{15}\right]^{+}(39.3 \%), 83\left[\mathrm{M}-\mathrm{C}_{8} \mathrm{H}_{17}\right]^{+}(46.7 \%), 73\left[\mathrm{M}-\mathrm{C}_{13} \mathrm{H}_{27}\right]^{+}(100 \%), 57} \\
{\left[\mathrm{M}-\mathrm{C}_{10} \mathrm{H}_{19}\right]^{+}(82.0 \%), 55\left[\mathrm{M}-\mathrm{C}_{10} \mathrm{H}_{21}\right]^{+}(66.7 \%)}\end{array}$ \\
\hline 26 & 9-octadecenoic acid & $\begin{array}{l}282\left[\mathrm{M}^{+}\right](0.3 \%), 265[\mathrm{M}-\mathrm{OH}]^{+}(3.3 \%), 223\left[\mathrm{M}-\mathrm{C}_{2} \mathrm{H}_{3} \mathrm{O}_{2}\right]^{+}(0.3 \%), 181\left[\mathrm{M}-\mathrm{C}_{5} \mathrm{H}_{9} \mathrm{O}_{2}\right]^{+}(0.3 \%), 153[\mathrm{M}- \\
\left.\mathrm{C}_{7} \mathrm{H}_{13} \mathrm{O}_{2}\right]^{+}(3.3 \%), 99\left[\mathrm{M}-\mathrm{C}_{11} \mathrm{H}_{19} \mathrm{O}_{2}\right]^{+}(4.0 \%), 85\left[\mathrm{M}-\mathrm{C}_{12} \mathrm{H}_{21} \mathrm{O}_{2}\right]^{+}(13.35), 55(100 \%), 43[\mathrm{M}- \\
\left.\mathrm{C}_{15} \mathrm{H}_{27} \mathrm{O}_{2}\right]^{+}(53.3 \%)\end{array}$ \\
\hline 27 & $\begin{array}{l}\text { methyl-14- } \\
\text { methylpentadecanoate }\end{array}$ & $\begin{array}{l}270\left[\mathrm{M}^{+}\right](40.6 \%), 241(13.1 \%), 227(29.8 \%), 199\left[\mathrm{M}-\mathrm{C}_{3} \mathrm{H}_{5} \mathrm{O}_{2}\right]^{+}(12.0 \%), 187(13.5 \%), 149(20.1 \%), \\
135(31.6 \%), 129\left[\mathrm{M}-\mathrm{C}_{10} \mathrm{H}_{21}\right]^{+}(24.8 \%), 87\left[\mathrm{M}-\mathrm{C}_{13} \mathrm{H}_{27}\right]^{+}(100 \%), 69(83.5), 57\left[\mathrm{M}-\mathrm{C}_{13} \mathrm{H}_{25} \mathrm{O}_{2}\right]^{+} \\
(38.4 \%)\end{array}$ \\
\hline 28 & methylpalmitate & $\begin{array}{l}270\left[\mathrm{M}^{+}\right](13.3 \%), 239\left[\mathrm{M}-\mathrm{CH}_{3} \mathrm{O}\right]^{+}(4.73 \%), 227\left[\mathrm{M}-\mathrm{C}_{3} \mathrm{H}_{7}\right]^{+}(10.0 \%), 213\left[\mathrm{M}-\mathrm{C}_{4} \mathrm{H}_{9}\right]^{+}(3.0 \%), 199 \\
{\left[\mathrm{M}-\mathrm{C}_{5} \mathrm{H}_{11}\right]^{+}(6.7 \%), 185\left[\mathrm{M}-\mathrm{C}_{6} \mathrm{H}_{13}\right]^{+}(6.7 \%), 171\left[\mathrm{M}-\mathrm{C}_{7} \mathrm{H}_{15}\right]^{+}(6.7 \%), 157\left[\mathrm{M}-\mathrm{C}_{8} \mathrm{H}_{17}\right]^{+}(3.3 \%), 143}\end{array}$ \\
\hline
\end{tabular}


International Journal of Science and Engineering Applications

Volume 6 Issue 03, 2017, ISSN-2319-7560 (Online)

\begin{tabular}{|c|c|c|}
\hline & & $\begin{array}{l}{\left[\mathrm{M}-\mathrm{C}_{9} \mathrm{H}_{19}\right]^{+}(18.0 \%), 129\left[\mathrm{M}-\mathrm{C}_{10} \mathrm{H}_{21}\right]^{+}(6.7 \%), 115\left[\mathrm{M}-\mathrm{C}_{11} \mathrm{H}_{23}\right]^{+}(3.3 \%), 97\left[\mathrm{M}-\mathrm{C}_{12} \mathrm{H}_{25}\right]^{+}(6.7 \%), 87} \\
{\left[\mathrm{M}-\mathrm{C}_{13} \mathrm{H}_{27}\right]^{+}(70.0 \%), 74(100 \%), 55(30.0 \%), 43(40.0 \%), 29(3.3 \%)}\end{array}$ \\
\hline 29 & $\begin{array}{l}\text { methyloctadeca-10,13- } \\
\text { diynoate }\end{array}$ & $\begin{array}{l}290\left[\mathrm{M}^{+}\right](0.2 \%), 284(0.2 \%), 231\left[\mathrm{M}-\mathrm{C}_{2} \mathrm{H}_{3} \mathrm{O}_{2}\right]^{+}(2.6 \%), 203\left[\mathrm{M}-\mathrm{C}_{4} \mathrm{H}_{7} \mathrm{O}_{2}\right]^{+}(6.4 \%), 147\left[\mathrm{M}-\mathrm{C}_{8} \mathrm{H}_{15} \mathrm{O}_{2}\right]^{+} \\
(7.7 \%), 133\left[\mathrm{M}-\mathrm{C}_{9} \mathrm{H}_{17} \mathrm{O}_{2}\right]^{+}(35.4 \%), 119\left[\mathrm{M}-\mathrm{C}_{10} \mathrm{H}_{19} \mathrm{O}_{2}\right]^{+}(14.3 \%), 105\left[\mathrm{M}-\mathrm{C}_{11} \mathrm{H}_{21} \mathrm{O}_{2}\right]^{+}(68.0 \%), 91 \\
(100 \%), 69\left[\mathrm{M}-\mathrm{C}_{14} \mathrm{H}_{21} \mathrm{O}_{2}\right]^{+}(11.0 \%), 57\left[\mathrm{M}-\mathrm{C}_{15} \mathrm{H}_{21} \mathrm{O}_{2}\right]^{+}(17.6 \%)\end{array}$ \\
\hline 30 & $\begin{array}{l}\text { methyloctadeca-12,15- } \\
\text { diynoate }\end{array}$ & $\begin{array}{l}290\left[\mathrm{M}^{+}\right](0.2 \%), 259\left[\mathrm{M}-\mathrm{CH}_{3} \mathrm{O}\right]^{+}(0.2 \%), 232(6.1 \%), 203\left[\mathrm{M}-\mathrm{C}_{4} \mathrm{H}_{7} \mathrm{O}_{2}\right]^{+}(0.4 \%), 175\left[\mathrm{M}-\mathrm{C}_{6} \mathrm{H}_{11} \mathrm{O}_{2}\right]^{+} \\
(4.6 \%), 147\left[\mathrm{M}-\mathrm{C}_{8} \mathrm{H}_{15} \mathrm{O}_{2}\right]^{+}(10.3 \%), 119\left[\mathrm{M}-\mathrm{C}_{10} \mathrm{H}_{19} \mathrm{O}_{2}\right]^{+}(16.2 \%), 105\left[\mathrm{M}-\mathrm{C}_{11} \mathrm{H}_{21} \mathrm{O}_{2}\right]^{+}(24.6 \%), 91 \\
{\left[\mathrm{M}-\mathrm{C}_{12} \mathrm{H}_{13} \mathrm{O}_{2}\right]^{+}(100 \%), 69(11.0 \%), 57(16.2 \%)}\end{array}$ \\
\hline 31 & methyllinolenate & $\begin{array}{l}292\left[\mathrm{M}^{+}\right](0.3 \%), 277\left[\mathrm{M}-\mathrm{CH}_{3}\right]^{+}(0.3 \%), 261\left[\mathrm{M}-\mathrm{CH}_{3} \mathrm{O}\right]^{+}(3.3 \%), 191\left[\mathrm{M}-\mathrm{C}_{5} \mathrm{H}_{9} \mathrm{O}_{2}\right]^{+}(3.3 \%), 163[\mathrm{M}- \\
\left.\mathrm{C}_{7} \mathrm{H}_{13} \mathrm{O}_{2}\right]^{+}(6.3 \%), 149\left[\mathrm{M}-\mathrm{C}_{8} \mathrm{H}_{15} \mathrm{O}_{2}\right]^{+}(16.7 \%), 135\left[\mathrm{M}-\mathrm{C}_{9} \mathrm{H}_{17} \mathrm{O}_{2}\right]^{+}(13.7 \%), 109\left[\mathrm{M}-\mathrm{C}_{11} \mathrm{H}_{19} \mathrm{O}_{2}\right]^{+} \\
(16.7 \%), 95\left[\mathrm{M}-\mathrm{C}_{12} \mathrm{H}_{21} \mathrm{O}_{2}\right]^{+}(60.0 \%), 79(100 \%), 55\left[\mathrm{M}-\mathrm{C}_{15} \mathrm{H}_{25} \mathrm{O}_{2}\right]^{+}(46.7 \%), 29\left[\mathrm{M}-\mathrm{C}_{17} \mathrm{H}_{27} \mathrm{O}_{2}\right]^{+} \\
(16.7 \%)\end{array}$ \\
\hline 32 & methylstearate & 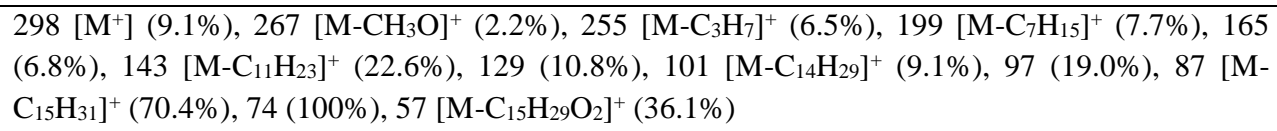 \\
\hline 33 & dehydroxyloliolide & $\begin{array}{l}180\left[\mathrm{M}^{+}\right](16.7 \%), 165\left[\mathrm{M}_{-} \mathrm{CH}_{3}\right]^{+}(6.7 \%), 155(23.3 \%), 147(26.7 \%), 135(37.3 \%), 124(16.7 \%), 111 \\
(91.7 \%), 97(36.7 \%), 83(100 \%), 69(56 \%), 55(70.0 \%)\end{array}$ \\
\hline 34 & geranylacetone & $\begin{array}{l}194\left[\mathrm{M}^{+}\right](0.3 \%), 179\left[\mathrm{M}-\mathrm{CH}_{3}\right]^{+}(0.7 \%), 151\left[\mathrm{M}-\mathrm{C}_{2} \mathrm{H}_{3} \mathrm{O}\right]^{+}(0.7 \%), 137\left[\mathrm{M}-\mathrm{C}_{3} \mathrm{H}_{5} \mathrm{O}\right]^{+}(10.0 \%), 123[\mathrm{M}- \\
\left.\mathrm{C}_{4} \mathrm{H}_{7} \mathrm{O}\right]^{+}(8.0 \%), 83\left[\mathrm{M}-\mathrm{C}_{7} \mathrm{H}_{11} \mathrm{O}\right]^{+}(9.7 \%), 69\left[\mathrm{M}-\mathrm{C}_{8} \mathrm{H}_{13} \mathrm{O}\right]^{+}(100 \%), 43(60.0 \%)\end{array}$ \\
\hline 35 & loliolide & 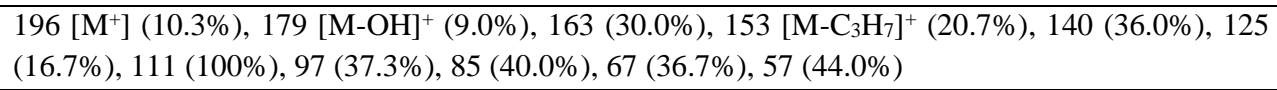 \\
\hline 36 & trans- $\beta$-caryophyllene & $\begin{array}{l}204\left[\mathrm{M}^{+}\right](0.5 \%), 189\left[\mathrm{M}-\mathrm{CH}_{3}\right]^{+}(11.3 \%), 175\left[\mathrm{M}-\mathrm{C}_{2} \mathrm{H}_{5}\right]^{+}(18.5 \%), 147\left[\mathrm{M}-\mathrm{C}_{4} \mathrm{H}_{9}\right]^{+}(54.2 \%), 135[\mathrm{M}- \\
\left.\mathrm{C}_{5} \mathrm{H}_{9}\right]^{+}(27.1 \%), 120\left[\mathrm{M}-\mathrm{C}_{6} \mathrm{H}_{12}\right]^{+}(85.8 \%), 93\left[\mathrm{M}-\mathrm{C}_{8} \mathrm{H}_{15}\right]^{+}(32.3 \%), 79\left[\mathrm{M}-\mathrm{C}_{9} \mathrm{H}_{17}\right]^{+}(100 \%), 67[\mathrm{M}- \\
\left.\mathrm{C}_{10} \mathrm{H}_{17}\right]^{+}(53.3 \%), 53\left[\mathrm{M}-\mathrm{C}_{11} \mathrm{H}_{19}\right]^{+}(29.3 \%)\end{array}$ \\
\hline 37 & 4(15),6-cadinadiene & $\begin{array}{l}204\left[\mathrm{M}^{+}\right](25.28 \%), 183(3.4 \%), 161\left[\mathrm{M}-\mathrm{C}_{3} \mathrm{H}_{7}\right]^{+}(100 \%), 133(15.8 \%), 119\left[\mathrm{M}-\mathrm{C}_{6} \mathrm{H}_{13}\right]^{+}(11.3 \%), 105 \\
{\left[\mathrm{M}-\mathrm{C}_{7} \mathrm{H}_{15}\right]^{+}(68.0 \%), 93\left[\mathrm{M}-\mathrm{C}_{8} \mathrm{H}_{15}\right]^{+}(40.6 \%), 71\left[\mathrm{M}-\mathrm{C}_{10} \mathrm{H}_{16}\right]^{+}(26.4 \%), 57(32.7 \%)}\end{array}$ \\
\hline 38 & 2,6,10-trimethyldodecane & $\begin{array}{l}212\left[\mathrm{M}^{+}\right](3.3 \%), 197\left[\mathrm{M}-\mathrm{CH}_{3}\right]^{+}(1.0 \%), 183\left[\mathrm{M}-\mathrm{C}_{2} \mathrm{H}_{5}\right]^{+}(4.0 \%), 169\left[\mathrm{M}-\mathrm{C}_{3} \mathrm{H}_{7}\right]^{+}(0.1 \%), 155[\mathrm{M}- \\
\left.\mathrm{C}_{4} \mathrm{H}_{9}\right]^{+}(3.3 \%), 141\left[\mathrm{M}-\mathrm{C}_{5} \mathrm{H}_{11}\right]^{+}(3.3 \%), 127\left[\mathrm{M}-\mathrm{C}_{6} \mathrm{H}_{13}\right]^{+}(16.7 \%), 113\left[\mathrm{M}-\mathrm{C}_{7} \mathrm{H}_{15}\right]^{+}(11.7 \%), 97[\mathrm{M}- \\
\left.\mathrm{C}_{8} \mathrm{H}_{17}\right]^{+}(21.0 \%), 85\left[\mathrm{M}-\mathrm{C}_{9} \mathrm{H}_{19}\right]^{+}(32.3 \%), 71\left[\mathrm{M}-\mathrm{C}_{10} \mathrm{H}_{21}\right]^{+}(73.3 \%), 57\left[\mathrm{M}-\mathrm{C}_{11} \mathrm{H}_{23}\right]^{+}(100 \%), 43[\mathrm{M}- \\
\left.\mathrm{C}_{12} \mathrm{H}_{24}\right]^{+}(83.3 \%)\end{array}$ \\
\hline 39 & capnellane-5- $\alpha$-ol & $\begin{array}{l}222\left[\mathrm{M}^{+}\right](17.3 \%), 207\left[\mathrm{M}-\mathrm{CH}_{3}\right]^{+}(89.3 \%), 189(16.7 \%), 151\left[\mathrm{M}-\mathrm{C}_{5} \mathrm{H}_{11}\right]^{+}(23.6 \%), 135(23.3 \%), 109 \\
{\left[\mathrm{M}-\mathrm{C}_{8} \mathrm{H}_{17}\right]^{+}(66.0 \%), 95\left[\mathrm{M}-\mathrm{C}_{9} \mathrm{H}_{19}\right]^{+}(84.0 \%), 81\left[\mathrm{M}-\mathrm{C}_{10} \mathrm{H}_{21}\right]^{+}(100 \%), 55\left[\mathrm{M}-\mathrm{C}_{12} \mathrm{H}_{23}\right]^{+}(59.35)}\end{array}$ \\
\hline 40 & pristine & $\begin{array}{l}268\left[\mathrm{M}^{+}\right](0.2 \%), 232(0.2 \%), 197\left[\mathrm{M}-\mathrm{C}_{5} \mathrm{H}_{11}\right]^{+}(0.3 \%), 183\left[\mathrm{M}-\mathrm{C}_{6} \mathrm{H}_{13}\right]^{+}(16.7 \%), 169\left[\mathrm{M}-\mathrm{C}_{7} \mathrm{H}_{15}\right]^{+} \\
(3.7 \%), 155\left[\mathrm{M}-\mathrm{C}_{8} \mathrm{H}_{17}\right]^{+}(6.3 \%), 141\left[\mathrm{M}-\mathrm{C}_{9} \mathrm{H}_{19}\right]^{+}(6.0 \%), 127\left[\mathrm{M}-\mathrm{C}_{10} \mathrm{H}_{21}\right]^{+}(10.0 \%), 113\left[\mathrm{M}-\mathrm{C}_{11} \mathrm{H}_{23}\right]^{+} \\
(20.0 \%), 99\left[\mathrm{M}-\mathrm{C}_{12} \mathrm{H}_{25}\right]^{+}(16.7 \%), 85\left[\mathrm{M}-\mathrm{C}_{13} \mathrm{H}_{27}\right]^{+}(40.7 \%), 71\left[\mathrm{M}-\mathrm{C}_{14} \mathrm{H}_{29}\right]^{+}(93.0 \%), 57\left[\mathrm{M}-\mathrm{C}_{15} \mathrm{H}_{31}\right]^{+} \\
(100 \%)\end{array}$ \\
\hline 41 & $\begin{array}{l}\text { 6,10,14-trimethyl-2- } \\
\text { pentadecanone }\end{array}$ & 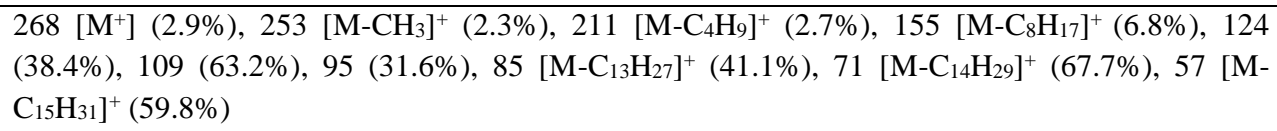 \\
\hline 42 & neophytadiene & $\begin{array}{l}278\left[\mathrm{M}^{+}\right](2.7 \%), 263\left[\mathrm{M}-\mathrm{CH}_{3}\right]^{+}(0.7 \%), 208\left[\mathrm{M}-\mathrm{C}_{5} \mathrm{H}_{10}\right]^{+}(1.0 \%), 193\left[\mathrm{M}-\mathrm{C}_{6} \mathrm{H}_{13}\right]^{+}(3.0 \%), 179[\mathrm{M}- \\
\left.\mathrm{C}_{7} \mathrm{H}_{15}\right]^{+}(4.7 \%), 165\left[\mathrm{M}-\mathrm{C}_{8} \mathrm{H}_{17}\right]^{+}(3.3 \%), 151\left[\mathrm{M}-\mathrm{C}_{9} \mathrm{H}_{19}\right]^{+}(3.3 \%), 137\left[\mathrm{M}-\mathrm{C}_{10} \mathrm{H}_{21}\right]^{+}(13.0 \%), 123[\mathrm{M}- \\
\left.\mathrm{C}_{11} \mathrm{H}_{23}\right]^{+}(66.7 \%), 109\left[\mathrm{M}-\mathrm{C}_{12} \mathrm{H}_{25}\right]^{+}(33.3 \%), 95\left[\mathrm{M}-\mathrm{C}_{13} \mathrm{H}_{27}\right]^{+}(96.7 \%), 82\left[\mathrm{M}-\mathrm{C}_{14} \mathrm{H}_{28}\right]^{+}(83.3 \%), 68 \\
{\left[\mathrm{M}-\mathrm{C}_{15} \mathrm{H}_{30}\right]^{+}(100 \%), 55\left[\mathrm{M}-\mathrm{C}_{16} \mathrm{H}_{31}\right]^{+}(66.7 \%)}\end{array}$ \\
\hline 43 & phytane & $\begin{array}{l}282\left[\mathrm{M}^{+}\right](0.3 \%), 197(1.3 \%), 183\left[\mathrm{M}-\mathrm{C}_{7} \mathrm{H}_{15}\right]^{+}(3.3 \%), 169\left[\mathrm{M}-\mathrm{C}_{8} \mathrm{H}_{17}\right]^{+}(6.3 \%), 141\left[\mathrm{M}-\mathrm{C}_{10} \mathrm{H}_{21}\right]^{+} \\
(10.0 \%), 127\left[\mathrm{M}-\mathrm{C}_{11} \mathrm{H}_{23}\right]^{+}(6.7 \%), 113(15.7 \%), 99\left[\mathrm{M}-\mathrm{C}_{13} \mathrm{H}_{27}\right]^{+}(20.0 \%), 85\left[\mathrm{M}-\mathrm{C}_{14} \mathrm{H}_{29}\right]^{+}(54.0 \%), \\
71\left[\mathrm{M}-\mathrm{C}_{15} \mathrm{H}_{31}\right]^{+}(87.7 \%), 57\left[\mathrm{M}-\mathrm{C}_{16} \mathrm{H}_{33}\right]^{+}(100 \%)\end{array}$ \\
\hline 44 & crocetane & $\begin{array}{l}282\left[\mathrm{M}^{+}\right](0.2 \%), 232(3.0 \%), 208(3.3), 183\left[\mathrm{M}-\mathrm{C}_{7} \mathrm{H}_{15}\right]^{+}(6.7 \%), 169\left[\mathrm{M}-\mathrm{C}_{8} \mathrm{H}_{17}\right]^{+}(10.7 \%), 155[\mathrm{M}- \\
\left.\mathrm{C}_{9} \mathrm{H}_{19}\right]^{+}(6.7 \%), 133\left[\mathrm{M}-\mathrm{C}_{11} \mathrm{H}_{17}\right]^{+}(17.7 \%), 91(40.0 \%), 71\left[\mathrm{M}-\mathrm{C}_{15} \mathrm{H}_{31}\right]^{+}(60.0 \%), 57\left[\mathrm{M}-\mathrm{C}_{16} \mathrm{H}_{33}\right]^{+} \\
(100 \%)\end{array}$ \\
\hline 45 & 14- $\beta$-H-pregnane & $\begin{array}{l}288\left[\mathrm{M}^{+}\right](0.3 \%), 280(5.0 \%), 250(11.7 \%), 220(30.7 \%), 189(20.0 \%), 165(20.7 \%), 141(17.0 \%), \\
111(43.0 \%), 83(75.0 \%), 57(100 \%)\end{array}$ \\
\hline 46 & phytol & $\begin{array}{l}296\left[\mathrm{M}^{+}\right](0.3 \%), 279[\mathrm{M}-\mathrm{OH}]^{+}(0.3 \%), 211\left[\mathrm{M}-\mathrm{C}_{5} \mathrm{H}_{9} \mathrm{O}\right]^{+}(0.3 \%), 197\left[\mathrm{M}-\mathrm{C}_{6} \mathrm{H}_{11} \mathrm{O}\right]^{+}(2.0 \%), 123[\mathrm{M}- \\
\left.\mathrm{C}_{12} \mathrm{H}_{13} \mathrm{O}\right]^{+}(22.3 \%), 111\left[\mathrm{M}-\mathrm{C}_{12} \mathrm{H}_{25} \mathrm{O}\right]^{+}(13.3 \%), 95\left[\mathrm{M}-\mathrm{C}_{14} \mathrm{H}_{17} \mathrm{O}\right]^{+}(16.7 \%), 83\left[\mathrm{M}-\mathrm{C}_{15} \mathrm{H}_{17} \mathrm{O}\right]^{+} \\
(24.0 \%), 71\left[\mathrm{M}-\mathrm{C}_{15} \mathrm{H}_{29} \mathrm{O}\right]^{+}(100 \%), 57\left[\mathrm{M}-\mathrm{C}_{16} \mathrm{H}_{31} \mathrm{O}\right]^{+}(33.3 \%), 43\left[\mathrm{M}-\mathrm{C}_{17} \mathrm{H}_{33} \mathrm{O}\right]^{+}(29.0 \%)\end{array}$ \\
\hline
\end{tabular}


International Journal of Science and Engineering Applications

Volume 6 Issue 03, 2017, ISSN-2319-7560 (Online)

\begin{tabular}{|c|c|c|}
\hline 47 & $\begin{array}{l}\text { 4,8,12,16-tetramethyl } \\
\text { heptadecan-1,4-olide }\end{array}$ & 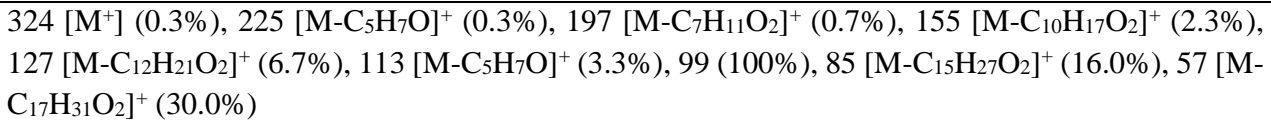 \\
\hline 48 & $\begin{array}{l}\text { 2-[4-methyl-6-(2,6,6- } \\
\text { trimethylcyclohex-1- } \\
\text { enyl)hexa-1,3,5- } \\
\text { trienyl]cyclohex-1-en-1- } \\
\text { carboxaldehyde }\end{array}$ & $\begin{array}{l}324\left[\mathrm{M}^{+}\right](0.2 \%), 274(3.2 \%), 243(2.3 \%), 217(6.1 \%), 192(3.2 \%), 165(6.8 \%), 147(33.9 \%), 133 \\
(9.1 \%), 119(18.5 \%), 105(31.6 \%), 91(100 \%), 69(17.4 \%), 55(24.8 \%)\end{array}$ \\
\hline 49 & gibberlline A3 & $\begin{array}{l}346\left[\mathrm{M}^{+}\right](1.0 \%), 327(8.0 \%), 300(2.0 \%), 281(46.7 \%), 253(13.3 \%), 207(100 \%), 177 \text { (4.0\%), } 159 \\
(6.7 \%), 96(10.0 \%), 73(18.3 \%), 55(11.0 \%)\end{array}$ \\
\hline 50 & Squalene & $\begin{array}{l}410\left[\mathrm{M}^{+}\right](0.7 \%), 367\left[\mathrm{M}-\mathrm{C}_{3} \mathrm{H}_{7}\right](0.3 \%), 341\left[\mathrm{M}-\mathrm{C}_{5} \mathrm{H}_{9}\right](2.7 \%), 281(3.3 \%), 207\left[\mathrm{M}-\mathrm{C}_{15} \mathrm{H}_{25}\right](6.7 \%), \\
191\left[\mathrm{M}-\mathrm{C}_{16} \mathrm{H}_{27}\right](3.3 \%), 137\left[\mathrm{M}-\mathrm{C}_{20} \mathrm{H}_{33}\right](16.3 \%), 123\left[\mathrm{M}-\mathrm{C}_{21} \mathrm{H}_{35}\right](10.0 \%), 69\left[\mathrm{M}-\mathrm{C}_{25} \mathrm{H}_{41}\right](100 \%), \\
55\left[\mathrm{M}-\mathrm{C}_{26} \mathrm{H}_{43}\right](2.3 \%)\end{array}$ \\
\hline 51 & vitamin $\mathrm{E}$ & 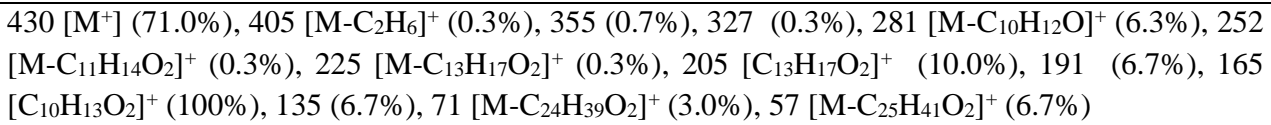 \\
\hline 52 & $\begin{array}{l}\text { 3,4,3',4'tetrahydrospirillox } \\
\text { anthin }\end{array}$ & $\begin{array}{l}600\left[\mathrm{M}^{+}\right](1.8 \%), 582(5.3 \%), 569\left[\mathrm{M}-\mathrm{CH}_{3} \mathrm{O}\right]^{+}(2.2 \%), 499\left[\mathrm{M}-\mathrm{C}_{6} \mathrm{H}_{13} \mathrm{O}\right]^{+}(2.2 \%), 470\left[\mathrm{M}-\mathrm{C}_{8} \mathrm{H}_{18} \mathrm{O}\right]^{+} \\
(6.8 \%), 459\left[\mathrm{M}-\mathrm{C}_{9} \mathrm{H}_{17} \mathrm{O}\right]^{+}(6.3 \%) 429(43.3 \%), 352\left[\mathrm{M}-\mathrm{C}_{17} \mathrm{H}_{28} \mathrm{O}\right]^{+}(11.5 \%), 340\left[\mathrm{M}-\mathrm{C}_{19} \mathrm{H}_{30} \mathrm{O}\right]^{+} \\
(33.9 \%), 326(27.1 \%), 282(16.2 \%), 259(27.1 \%), 241(20.3 \%), 215(49.2 \%), 193(33.3 \%), 169[\mathrm{M}- \\
\left.\mathrm{C}_{31} \mathrm{H}_{43} \mathrm{O}\right]^{+}(29.3 \%), 121(61.0 \%), 115\left[\mathrm{M}-\mathrm{C}_{35} \mathrm{H}_{49} \mathrm{O}\right]^{+}(42.7 \%), 105(38.3 \%), 69(100 \%)\end{array}$ \\
\hline 53 & 1-methyl-9H-fluorine & $\begin{array}{l}180\left[\mathrm{M}^{+}\right](70.0 \%), 165\left[\mathrm{M}-\mathrm{CH}_{3}\right]^{+}(100 \%), 152\left[\mathrm{M}-\mathrm{C}_{2} \mathrm{H}_{4}\right]^{+}(15.7 \%), 141(7.3 \%), 128(10.0 \%), 111 \\
(10.0 \%), 97(26.0 \%), 83(20.0 \%), 69(20.0 \%), 57(23.3 \%)\end{array}$ \\
\hline 54 & Dioctyladipate & $\begin{array}{l}341\left[\mathrm{M}^{+}\right](4.5 \%), 283(2.5 \%), 241\left[\mathrm{M}-\mathrm{C}_{8} \mathrm{H}_{17} \mathrm{O}\right]^{+}(18.1 \%), 199\left[\mathrm{M}-\mathrm{C}_{10} \mathrm{H}_{19} \mathrm{O}_{2}\right]^{+}(9.7 \%), 167(5.6 \%), \\
147(40.6 \%), 129\left[\mathrm{M}-\mathrm{C}_{14} \mathrm{H}_{25} \mathrm{O}_{3}\right]^{+}(100 \%), 113\left[\mathrm{M}-\mathrm{C}_{14} \mathrm{H}_{25} \mathrm{O}_{4}\right]^{+}(2.2 \%), 83(32.5), 71\left[\mathrm{M}-\mathrm{C}_{10} \mathrm{H}_{19} \mathrm{O}_{2}\right]^{+} \\
(36.1 \%), 57\left[\mathrm{M}-\mathrm{C}_{17} \mathrm{H}_{31} \mathrm{O}_{4}\right]^{+}(56,4 \%)\end{array}$ \\
\hline
\end{tabular}

\subsubsection{Antioxidant activity assessment}

\subsubsection{Free radical scavenging method} (ABTS)

For each of the investigated fractions $(2 \mu \mathrm{l})$ of ABTS solution was added to $3 \mu \mathrm{MnO}_{2}$ solution $(25 \mathrm{mg} / \mu \mathrm{l})$, all were prepared in $(5 \mu \mathrm{l})$ aqueous phosphate buffer solution ( $\mathrm{pH} 7,0.1 \mathrm{M})$. The mixture was shaken, centrifuged, filtered and the absorbance of the resulting green blue solution (ABTS radical solution) at 734 $\mathrm{nm}$ was adjusted to approx. ca. 0.5. Then, $50 \mu \mathrm{l}$ of $(2 \mu \mathrm{M})$ solution of the tested fraction and the isolated compound in spectroscopic grade $\mathrm{MeOH} /$ phosphate buffer (1:1) was added. The absorbance was measured and the reduction in color intensity was expressed as inhibition percentage. L-ascorbic acid was used as standard antioxidant (positive control). Blank sample was run without $\mathrm{ABTS}$ and using $\mathrm{MeOH} /$ phosphate buffer (1:1) instead of tested fractions. Negative control was run with $\mathrm{ABTS}$ and $\mathrm{MeOH} /$ phosphate buffer (1:1) only.

\subsubsection{Cytotoxicity assay}

The cell lines MCF-7, HePG-2 and PC3 were used to determine the inhibitory effects of extracts on cell growth using the MTT assay (Mosmann and Immunol, 1983; Denizot et al., 1986). This colorimetric assay is based on the conversion of the yellow tetrazolium bromide (MTT) to a purple formazan derivative by mitochondrial succinate dehydrogenase in viable cells. Cell lines were cultured in RPMI-1640 medium with $10 \%$ fetal bovine serum. Antibiotics added were 100 units / $\mu$ penicillin and $100 \mu \mathrm{g} / \mu \mathrm{l}$ streptomycin at $37^{\circ} \mathrm{C}$ in a $5 \% \mathrm{CO}_{2}$ incubator. The cell lines were seeded in a 96-well plate at a density of a $1.0 \times 10^{4}$ cells/well at $37{ }^{\circ} \mathrm{C}$ for $48 \mathrm{~h}$ under $5 \% \mathrm{CO}_{2}$. After incubation the cells were treated with different concentration of the fractions and isolated compound and incubated for $24 \mathrm{~h}$. After $24 \mathrm{~h}$ of the treatment, $20 \mu \mathrm{l}$ of MTT solution at $5 \mathrm{mg} / \mu \mathrm{l}$ was added and incubated for $4 \mathrm{~h}$. Dimethyl sulfoxide (DMSO) in volume of $100 \mu 1$ is added into each well to dissolve the purple formazan formed. The colorimetric assay is measured and recorded at absorbance of $570 \mathrm{~nm}$ using a plate reader (EXL 800). The relative cell viability was calculated from the formula:

$$
\begin{aligned}
& \% \text { Relative cell viability } \\
& =\frac{\text { Absorbance } 570 \text { of treated samples }}{\text { Absorbance } 570 \text { of untreated sample }} \times 100
\end{aligned}
$$

\section{REFERENCES}

[1] Angiosperm Phylogeny Website. Retrieved 15 July 2014.

[2] Fryxell P. A. 1997a. The American genera of MalvaceaeII. Brittonia. 49: 204-269.

[3] Al-Gohary H. 2008. Floristic Composition of Eleven Wadis in Gebel Elba, Egypt. IJAB. 10: 151-160.

[4] Shaltout K, Sheded G. M., and Salem A. 2010. Vegetation spatial heterogeneity in a hyper arid Biosphere Reserve area in North Africa. Acta Bot. Croat. 69: 31-46. 
[5] Alshamy M. M. 2016. Ecological study on wild vegetation of palm fields across some oases in western Desert, Egypt. CATRINA. 15: in press.

[6] Qing ma shu. 2007. Flora of China. 12: 275-279.

[7] Boulos L. 2002. Flora of Egypt. Al Hadara Publishing, Cairo, Egypt. 3: 229-231.

[8] Vaghasiya Y., Chanda S., and Turk J. 2007. Biol. 31: 243248.

[9] Ali S., Yasmeen S., Afza N., Malik A., Iqbal L., Lateef M., Riaz N., and Ashraf M. J. 2009. Asian Nat Prod Res. 11: 457-464.

[10] Eldahshan O. A. 2010. Isolation and Structure Elucidation of Phenolic Compounds of Carob Leaves Grown in Egypt. Curr. Res. J. Biol. Sci. 3: ISSN: 2041-0778.

[11] Ibrahim A., Khalifa S., khafagi I., Youssef D., Khan S., Mesbah M. k., and Khan I. 2008. Microbial Metabolism of Biologically Active Secondary Metabolites from Nerium oleander L. Chem. Pharm. Bull. 56: 1256-1257.

[12] Lissi E., Modak B., Torres R., Escobar J., and Urza A. 1999. Free Radical Res. 30: $471-477$.

[13] El-Gazar A. B. A., Youssef A. M. S., Youssef M. M., AbuHashem A. A., Badria F. A., and Eur. J. 2009. Med. Chem. 44: $609-624$.

[14] Aeschlach R., Loliger J., Scott C. B., Murcia A., Butler J., Halliwell B., and Aruoma I. O. 1994. Food Chem. Toxicol. 32: $31-36$.

[15] Stylianakis A., Kolocouris N., Kolocouris G., Fytas G. B., Foscolos E., Padalko J., Neyts D., and Clerq E. 2003. Bioorg, Med. Chem. Lett. 13: 1699 - 1703.

[16] Mosmann T., and Immunol J. 1983. Methods. 65: 55-63.

[17] Denizot F., Lang R., and Immunol J. 1986. Methods. 22: 271-277.

[18] Mauceri H. J., Hanna N. N., Beckett M. A., Gorski D. H., Staba M. J., Stellato K. A., Bigelow K., Heimann R, Gately S., Dhanabal M., Soff G. A., Sukhatme V. P., Kufe D. W., and Weichselbaum R. R. 1998. Combined effects of agiostatin and ionizing radiation in antitumour therapy. Nature. 394: 287-291. 